\title{
ICOS eddy covariance flux-station site setup: a review
}

Corinna Rebmann ${ }^{1 *}$, Marc Aubinet $^{2}$, HaPe Schmid ${ }^{3}$, Nicola Arriga ${ }^{4}$, Mika Aurela ${ }^{5}$, George Burba ${ }^{6,7}$, Robert Clement ${ }^{8}$, Anne De Ligne ${ }^{2}$, Gerardo Fratini ${ }^{6}$, Bert Gielen ${ }^{4}$, John Grace $^{8}$, Alexander Graf ${ }^{9}$, Patrick Gross $^{10}$, Sami Haapanala ${ }^{11}$, Mathias Herbst ${ }^{12}$, Lukas Hörtnagl ${ }^{13}$, Andreas Ibrom ${ }^{14}$, Lilian Joly ${ }^{15}$, Natascha Kljun ${ }^{16}$, Olaf Kolle ${ }^{17}$, Andrew Kowalski ${ }^{18}$, Anders Lindroth ${ }^{19}$, Denis Loustau ${ }^{20}$, Ivan Mammarella ${ }^{21}$, Matthias Mauder ${ }^{3}$,Lutz Merbold ${ }^{13,22}$, Stefan Metzger ${ }^{23,24}$, Meelis Mölder ${ }^{19}$, Leonardo Montagnani ${ }^{25}$, Dario Papale $^{26}$, Marian Pavelka ${ }^{27}$, Matthias Peichl $^{28}$, Marilyn Roland $^{4}$, Penélope Serrano-Ortiz ${ }^{29}$, Lukas Siebicke $^{30}$, Rainer Steinbrecher ${ }^{3}$, Juha-Pekka Tuovinen ${ }^{5}$, Timo Vesala ${ }^{21,31}$, Georg Wohlfahrt ${ }^{32}$, and Daniela Franz ${ }^{33}$

${ }^{1}$ Department Computational Hydrosystems, Helmholtz Centre for Environmental Research - UFZ, Permoserstraße 15, 04318, Leipzig, Germany

${ }^{2}$ TERRA Teaching and Research Centre, Gembloux Agro-Bio Tech, University of Liege, 5030, Gembloux, Belgium

${ }^{3}$ Institute of Meteorology and Climate Research - Atmospheric Environmental Research, Karlsruhe Institute of Technology (KIT), Kreuzeckbahnstraße 19, 82467, Garmisch-Partenkirchen, Germany

${ }^{4}$ Research Centre of Excellence Plants and Ecosystems (PLECO), University of Antwerp. Universiteitsplein 1, 2610, Wilrijk, Belgium ${ }^{5}$ Finnish Meteorological Institute, P.O. Box 503, 00101, Helsinki, Finland

${ }^{6}$ Research and Development, LI-COR Biosciences, 4421 Superior St., Lincoln, NE 68504, USA

${ }^{7}$ R. B. Daugherty Water for Food Institute, School of Natural Resources, University of Nebraska, Lincoln, Nebraska 68583, USA

${ }^{8}$ School of Geosciences, The University of Edinburgh, West Mains Road, EH9 3JN, Edinburgh, UK

${ }^{9}$ Institute of Bio- and Geosciences, Agrosphere (IBG-3), Forschungszentrum Jülich, Wilhelm-Johnen-Straße, 52428 Jülich, Germany

${ }^{10}$ UMR EEF, French National Institute for Agricultural Research (INRA), 54280 Champenoux, France

${ }^{11}$ Suvilumi, Ohrahuhdantie 2 B, 00680 Helsinki, Finland

${ }^{12}$ Centre for Agrometeorological Research (ZAMF), German Meteorological Service, Bundesallee 33, 38116 Braunschweig, Germany

${ }^{13}$ Department of Environmental System Sciences, Institute of Agricultural Sciences, ETH Zürich, Universitätstrasse 2, 8092, Zürich, Switzerland

${ }^{14}$ Department of Environmental Engineering, Technical University of Denmark, Bygningstorvet, 2800 Kgs. Lyngby, Denmark

${ }^{15}$ Groupe de Spectrométrie Moléculaire et Atmosphérique GSMA, Université de Reims-Champagne Ardenne, UMR CNRS 7331, Moulin de la Housse, BP 1039, 51687, Reims 2, France

${ }^{16}$ Centre for Environmental and Climate Research, Lund University, Sölvegatan 37, 22362 Lund, Sweden

${ }^{17}$ Max Planck Institute for Biogeochemistry, P.O. Box 1001 64, 07701, Jena, Germany

${ }^{18}$ Andalusian Centre for Environmental Research (CEAMA-IISTA), University of Granada, 18071, Granada, Spain

${ }^{19}$ Department of Physical Geography and Ecosystem Science, Lund University, Sölvegatan 12, 22362, Lund, Sweden

${ }^{20}$ INRA UMR 1391 ISPA, F-33140, Villenave D’Ornon, France

${ }^{21}$ Institute for Atmospheric and Earth System Research/Physics, Faculty of Sciences, POBox 68, FI-00014 University of Helsinki, Finland

${ }^{22}$ Mazingira Centre, International Livestock Research Institute (ILRI), P.O. Box 30709, 00100, Nairobi, Kenya

${ }^{23}$ National Ecological Observatory Network, Battelle, 1685 38th Street, CO 80301 Boulder,

${ }^{24}$ University of Wisconsin-Madison, Dept. of Atmospheric and Oceanic Sciences, 1225 West Dayton Street, Madison, WI 53706, USA

${ }^{25}$ Faculty of Science and Technology, Piazza Università 1, 39100 Bolzano, Italy

${ }^{26}$ Department for Innovation in Biological, Agro-food and Forest Systems (DIBAF), University of Tuscia, Largo dell’Università Blocco D, 01100, Viterbo, Italy

${ }^{27}$ Department of Matters and Energy Fluxes, Global Change Research Institute, Czech Academy of Sciences, Bělidla 986/4a, 60300, Brno, Czech Republic 


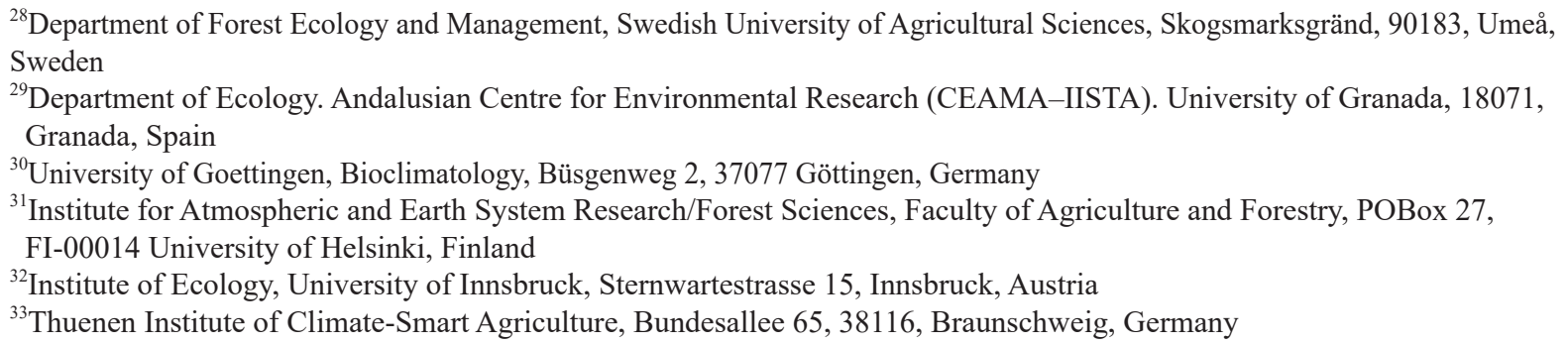

Received February 2, 2018; accepted July 11, 2018

Abstract. The Integrated Carbon Observation System Research Infrastructure aims to provide long-term, continuous observations of sources and sinks of greenhouse gases such as carbon dioxide, methane, nitrous oxide, and water vapour. At ICOS ecosystem stations, the principal technique for measurements of ecosystem-atmosphere exchange of GHGs is the eddy-covariance technique. The establishment and setup of an eddy-covariance tower have to be carefully reasoned to ensure high quality flux measurements being representative of the investigated ecosystem and comparable to measurements at other stations. To fulfill the requirements needed for flux determination with the eddycovariance technique, variations in GHG concentrations have to be measured at high frequency, simultaneously with the wind velocity, in order to fully capture turbulent fluctuations. This requires the use of high-frequency gas analysers and ultrasonic anemometers. In addition, to analyse flux data with respect to environmental conditions but also to enable corrections in the post-processing procedures, it is necessary to measure additional abiotic variables in close vicinity to the flux measurements. Here we describe the standards the ICOS ecosystem station network has adopted for GHG flux measurements with respect to the setup of instrumentation on towers to maximize measurement precision and accuracy while allowing for flexibility in order to observe specific ecosystem features.

Keyw ords: ICOS, tower set up, protocol, greenhouse gas, eddy covariance technique

\section{INTRODUCTION}

Knowledge on the response of greenhouse gas (GHG) fluxes between ecosystems and the atmosphere to climatic variability is crucial for the prediction of future atmospheric GHG levels. The balance between GHG sources and sinks is regulated by biotic and abiotic factors and is still highly uncertain (e.g. Le Quéré et al., 2016). Several networks distributed over the globe such as Euroflux, Ameriflux, Asiaflux, OzFlux or NEON (Aubinet et al., 2000; Baldocchi et al., 2001; Keller et al., 2008; Yamamoto et al., 2005) aim to satisfy the needs for high quality data and to reduce uncertainty in trace gas flux observations above different natural and anthropogenic influenced ecosystems. Evolving from previous European GHG and carbon observation programs and networks, the panEuropean research infrastructure ICOS (Integrated Carbon Observation System) established as an observation network for greenhouse gases (GHG) across the European conti- nent (Franz et al., 2018). ICOS captures the requirements for an environmental research infrastructure by providing long-term series of harmonized high-precision data, and integrates observations in the atmosphere, at terrestrial ecosystems and oceans. Within the ecosystem component of ICOS, fluxes of $\mathrm{CO}_{2}$, methane $\left(\mathrm{CH}_{4}\right)$, water vapour $\left(\mathrm{H}_{2} \mathrm{O}\right)$ and heat are measured together with ecosystem variables needed to understand the processes behind the exchange dynamics. In ecosystem-atmosphere exchange studies, the eddy-covariance (EC) flux measurement technique has become the methodology of choice for the determination of trace gas exchange (Baldocchi, 2003). It is therefore the most important observation component at ICOS ecosystem stations, where the instruments used for flux measurements are deployed from masts or towers, at suitable heights above the ecosystem of interest.

The EC method is based on simplifications of the mass balance equation, and its integration over a control volume which extends horizontally on a representative surface and vertically from the soil level to the measurement height (Finnigan et al., 2003; Foken et al., 2012; Nicolini et al., 2018). After applying the Reynolds decomposition, spatial integration over a control volume of height $z$, neglecting the horizontal turbulent flux divergence and the horizontal variation of the vertical flux, the flux $F$ of a scalar constituent $\chi_{s}$ exchanged by an ecosystem is given by (Aubinet et al., 2005; Feigenwinter et al., 2010; Foken et al., 2012; Nicolini et al., 2018):

$$
F_{\chi_{s}}=\left.\frac{1}{V_{m}} \overline{w^{\prime} x_{s}^{\prime}}\right|_{z}+\int_{0}^{z} \frac{1}{V_{m}} \frac{\partial \bar{T}_{s}(z)}{\partial t} d z+\int_{0}^{z} \frac{1}{V_{m}} \bar{w}(z) \frac{\partial \bar{T}_{s}(z)}{\partial z} d z+\int_{0}^{z} \frac{1}{V_{m}}\left(\bar{u}(z) \frac{\partial \bar{T}_{s}(z)}{\partial x}+\bar{v}(z) \frac{\partial \bar{T}_{s}(z)}{\partial y}\right) d z,
$$

where: $V_{m}$ is the molar volume of dry air, $u, v$ and $w$ are the wind components, respectively, in the direction of the mean wind $(x)$, the lateral wind $(y)$ and normal to the surface $(z)$. Overbars refer to the Reynolds averaging operator. The first term on the right hand side (RHS) of Eq. (1) is the turbulent vertical flux $F \chi_{\text {s-turb }}$ at height $z$, which is all that is left over after vertical integration of the flux divergence and can be measured by an EC system at the reference height $z$ above the surface roughness elements. The second term on the RHS refers to the rate of change in storage of the scalar $F \chi_{s-s t o r}$, and can be estimated from vertical profile 
measurements as described in a related paper of this issue about storage terms. The third and fourth terms denote the non-turbulent vertical and horizontal advection fluxes, respectively. Lateral gradients can be neglected in conditions of atmospheric stationarity and horizontal homogeneity. Often, advection is considered on a campaign basis due to the need of intensive measurement equipment and the difficulties in measuring all terms with the required accuracy (e.g. Aubinet et al., 2010; Feigenwinter et al., 2008). In standard applications, Eq. (1) reduces to the first two terms on the RHS and Eq. (1) becomes:

$$
F_{\chi_{s}}=F \chi_{s-t u r b}+F \chi_{s-s t o r}
$$

For the case of carbon dioxide $\left(\mathrm{CO}_{2}\right), F \chi_{s}$ is defined as the net ecosystem exchange (NEE), the sum of $\mathrm{CO}_{2}$ released from the soil and plants and $\mathrm{CO}_{2}$ taken up by plants through photosynthesis.

EC measurements are performed on a tower or a mast located inside an ecosystem and thus enable the most direct and accurate way to estimate turbulent fluxes of energy and gases without disturbing the ecosystem. In addition, the area sampled with the EC method possesses longitudinal dimensions ranging between a hundred meters and some kilometers (Schmid, 1994). However, the area represented by EC measurements - the source area or footprint - is a complex function of the observation level, surface roughness, and atmospheric conditions (Schmid, 2002; Vesala et al., 2008; Rannik et al., 2012). EC measurements can be performed almost continuously over extended periods of time ( $>$ a decade) and the averaging over long periods reduces random sampling errors to relatively small values (Baldocchi, 2003). Automated data acquisition and post-processing procedures allow to ensure data coverage, quality assurance and control (QA/QC, Foken et al., 2012; Mauder et al., 2013; Rebmann et al., 2012; Vickers and Mahrt, 1997).

At ICOS ecosystem stations, the instruments used for flux measurements are deployed from masts or towers, at suitable heights above the ecosystem of interest. Highfrequency gas analysers and sonic anemometers are key elements in the measurements of $\mathrm{CO}_{2}$ and $\mathrm{H}_{2} \mathrm{O}$ exchange using the $\mathrm{EC}$ technique. However, neither an international standard nor a list of recommendations for the sensors have been firmly established as each of the gas analysers as well as the sonic anemometers have their advantages and disadvantages. Depending on climatic conditions, personal experience and financial situation of the research groups, different instruments are currently deployed. In a long-term environmental research infrastructure it is crucial to ensure maximum comparability between stations. For this reason, standardised methods and sensors are required (Franz et al., 2018; Hinckley et al., 2016), despite the lack of knowledge on systematic and random differences between different implementations (Baldocchi, 2003; Haslwanter et al., 2009; Lasslop et al., 2008; Richardson et al., 2012), especially over medium and long-term time scales (e.g. several years). As a result, within the ecosystem component of ICOS scientific experts from different observations networks across the globe agreed based on best knowledge at this time to select a single model in each instrument category for the first period of the project and a single standardised way of the instrument setup and configuration across all stations. It should be noted here that design refinements, improvements and exchanges of sensors are desired and have to be expected during the succession of a long-term research project. In this paper, we summarise the present best practice application of the EC method as agreed among experts across the globe and concentrate on the instrumentation needed to determine sensible $(\mathrm{H})$ and latent heat $(\lambda \mathrm{E})$ and carbon dioxide $\left(\mathrm{F}_{\mathrm{CO}_{2}}\right)$ fluxes together with the sensors for variables that are needed for reproducible flux data evaluation at ICOS ecosystem stations. We present the background and rationale for the selection of gas analyser-anemometer pair, setup and guidelines for operational activities during the initial phase of ICOS-RI. In addition, the selection of a flux tower location and requirements for the tower design will be briefly discussed since much of this information is already provided in other publications such as e.g. Burba (2013), Munger et al. (2012) and some design and instrumental criteria are adopted from networks such as the National Ecological Observatory Network (NEON: https:// www.neonscience.org/) and AmeriFlux (http://ameriflux. lbl.gov/), all of them contributing to the network of networks: FLUXNET (Baldocchi et al., 2001; https://fluxnet. fluxdata.org/). Trace gas fluxes beyond $\mathrm{CO}_{2}$ and $\mathrm{H}_{2} \mathrm{O}$, issues accounting for storage fluxes as well as post-processing procedures are treated in related papers of this issue.

\section{METHODOLOGY}

As part of the requirement for a high level of harmonization across different sites, all primary data collected to capture carbon and water fluxes at ICOS ecosystem stations are generated according to 'protocols' that were developed within the ICOS ecosystem community by external and internal experts in their respective areas over the last couple of years. From these protocols, 'instructions' where extracted by the Ecosystem Thematic Centre (ETC), which include details about the technical implementation of all data to be acquired at ICOS ecosystem stations. The instructions are available via the Carbon Portal (www. icos-etc.eu/documents/instructions). All continuous and campaign-based data are processed centrally at the ETC. Despite the goal to collect high-quality data at all sites that contribute to the network, compromises between scientific requirements, engineering standards, cost and practicability might become necessary. Therefore, necessary adjustments need to be discussed and agreed on with the ETC prior to implementation. 
Core measurements of ICOS ecosystem stations are biosphere-atmosphere $\mathrm{CO}_{2}$ and water fluxes determined via the EC technique. To ensure inter-site comparability across the network, the standardisation starts with the establishment of the field infrastructure, namely the mast or tower to achieve being above the canopy of an ecosystem and the thorough installation of all instruments including documentation. In addition to flux measurements, at each ICOS ecosystem station a large set of auxiliary abiotic variables are measured that are essential for correction of EC data (Foken et al., 2012; Ibrom et al., 2007a,b), interpretation of the observed fluxes and the parameterization of land surface models. Besides the continuous acquisition of primary meteorological variables, site characteristics, carbon and nitrogen stocks in biomass and soils as well as survey campaigns of e.g. leaf area index and understory harvest are considered and described in related papers of this issue.

\section{SITE SELECTION AND SITE CHARACTERIZATION}

\section{Principles and practical issues of flux site selection}

The establishment and setup of a new EC tower has to be carefully reasoned to ensure flux measurements of high quality and representativeness of the investigated ecosystem. Detailed requirements for setting up an EC station are reviewed in the respective literature (Lee et al., 2004; Burba, 2013; Baldocchi et al., 1988). First steps to be considered are the tower design and location, which is often defined by ecosystem type, power availability, permissions and infrastructural limitations or accessibility.

Site selection should minimize systematic biases that may be caused by changing land cover within the flux source area, by topography which may result in non-negligible advection, and by obstacles that can cause flow distortion (Belcher et al., 2008; Rannik et al., 2006; Sogachev et al., 2005) while being fully representative of the system investigated. Such disturbances are contradicting the assumptions made in the theoretical derivation of the EC equations and can hardly be accounted for in the post-processing.

The contribution of the station to the network to cover different geography, climate, elevation, biomes, stand ages and different management types are important site selection criteria within ICOS. Ideally, each major ecosystem type should be represented in each major (pedo-) climatic region (Zscheischler et al., 2017). For this, a pre-screening of aspired measuring sites jointly with the Ecosystem Thematic Centre (ETC) of ICOS is recommended to evaluate the coverage within a region.

There are several quantitative approaches to this question. For instance, NEON (http://www.neonscience.org/) uses a cluster analysis over environmental variables following Hargrove and Hoffman $(1999,2004)$ with a system engineering approach to identify regional ecological representativeness. So far, in ICOS, new stations have been established to cover ecosystem types that were not present in the previous networks (such as lakes or urban sites) or have turned out to be vulnerable to future climate change. The uncertainty in predicting GHG and energy fluxes from EC stations to continental scales is depending on the number and spatial distribution of samples. Analysis with Artificial Neural Networks can support the selection of additional stations to quantify the representativeness of continental to global flux estimates (Papale et al., 2015).

Once an ecosystem or a region of interest has been identified, the spatial representativeness and location bias of measurements should be determined a-priori (Schmid, 1997; Schmid and Lloyd, 1999; Kim et al., 2006) by ground-based investigations of the heterogeneity of e.g. leaf area index, crown closure, or soil conditions in combination with remote sensing information. Ideally, the target area of interest within the ecosystem has to be large enough to be clearly identifiable by satellite and/or a model grid cell in addition to general fetch requirements for EC measurements. However, there are typical European landscapes where this criterion is difficult to meet in practice even though their value and potential to reduce uncertainties of surface GHG fluxes for a network such as ICOS would be high (Kaminski and Rayner, 2017). Logically, exceptions from the standard approach may become necessary and site-specific characteristics of new locations have to be evaluated by expert groups within the ETC and the Monitoring Station Assembly (MSA) of ICOS-Ecosystems in detail with respect to their value to the network, fetch uniformity, and orography, respectively.

\section{Practical issues for site selection}

Before establishing a new ICOS ecosystem station, long-term access and collaboration with the owners have to be negotiated. This requires for example permits with respect to natural reserve regulations that influence access and station construction. Year-round regular road access, availability of a grid power and data link (e.g. landline data connection, mobile phone network, microwave link, satellite link) are preferable, but should not be limiting factors in case a site would scientifically fit into the network and high data quality can be ensured. Electrical power (at least 2.5-3 kW with a continuous year-round availability) has to be ensured for ICOS Class 1 and Class 2 stations (highest and intermediate levels of standardisation requirements, respectively, Franz et al., 2018; Gielen, et al., 2017), while avoiding exhaust from e.g. diesel generators. The tower safety has to be ensured on a long-term basis as well (for example, trees may be too close to the tower construction). Safety regulations must be fulfilled when working on the tower scaffoldings and the masts. 


\section{Site characterization}

Each ecosystem flux station within the ICOS network has to be characterized with respect to the ecosystem type such as forest, grassland, agricultural land, wetland, or other ecosystem types respectively. Information that stays unchanged such as geographic conditions and coordinates, elevation, topographic setting, slope, land use history, soils, and climate (long-term, usually 30-year averages for temperature and precipitation), have to be reported to the metadata database part via the 'Biological, Ancillary, Disturbance and Metadata' (BADM) system. The BADM system is based on an international system agreed across the flux networks globally, in particular between AmeriFlux and European networks (Baldocchi, 2014), http://ameriflux. lbl.gov/data/badm-data-templates/, and ICOS Ecosystem Instructions at http://www.icos-etc.eu/icos/documents/ instructions/badm) with specific changes for ICOS data. Station-related metadata concerning the instrumentation, the location of measurement systems, and alignment of booms have to be reported to the ETC. Ecosystem type details, such as stocking rate or biomass per area, have to be described according to the respective protocols for ancillary data and in related papers of this issue. Characteristics that may change over time, such as species composition, canopy structure and scales of heterogeneity also have to be communicated via the metadata system.

\section{TOWER PLACEMENT AND DESIGN}

\section{Placement of the tower and dimension of mast}

The general tower setup requirements described here are primarily based on principles described in Munger et al. (2012). The key point for the location of an EC tower is to represent the ecosystem of interest, hence the basic requirements (e.g., adequate fetch conditions for all desired wind directions, homogeneity, etc.) have to be met. For the selection of the tower type, an optimal solution that best achieves the precision and accuracy required to satisfy the scientific objectives, such as minimizing flow distortion and biases by preferential airflows, and maintaining the ecological integrity of the site has to be found. The specific tower design depends on the type of the ecosystem. Over short vegetation or small obstacles, a slim mast is sufficient. Over tall vegetation, a bigger tower is needed that is slim enough to avoid influences on the wind field but also robust enough to ensure safe access for maintenance and to with stand environmental extremes over the lifetime. Guyed scaffold towers can be used for heights above $30 \mathrm{~m}$, while freestanding towers may be used for lower heights. In any case, a cross-section of $2 \times 3 \mathrm{~m}$ should not be exceeded (Munger et al., 2012). General requirements for the placement and design of the EC tower are listed in the appendix A1.

The presence of the tower structure itself can significantly affect the airflow of interest by distorting the wind velocity and wind direction nearby. Although such dis- tortion is particularly important for tall tower structures over forests, short crops and grasslands are also affected, especially in the presence of the nearby housing used to store instrumentation, computers and other hardware. Such sources of flow distortion should be minimized as much as practically feasible. The remaining distortion and chimney effects by the tower structure should be investigated in special campaigns (Serafimovich et al., 2011) or via modelling approaches (Griessbaum and Schmidt, 2009).

Natural airflow streamlines diverge when encountering an obstacle at every scale, from the multi-meter tower structure to the few-millimeter instrument spar or cable, resulting in the separation of the very same flow which is used to compute the fluxes. Flow distortion affects the measurements in a way that is difficult-to-impossible to see and correct, and should be minimized with regard to the principles as listed in the appendix A1.

\section{Height of the measurement (based on Munger et al., 2012)}

The consistency of measurement heights among towers in different ecosystems within the ICOS network is vital to provide comparable data with similar uncertainties. The following criteria have to be considered: (1) sensors should be placed high enough to capture the exchange fluxes in the well-mixed surface layer above the plant canopy and simultaneously to avoid influences on the measurements by the roughness layer or individual roughness elements close to the tower. (2) sensors have to be placed low enough to ensure that the footprint does not extend beyond the fetch of interest during stable atmospheric conditions (e.g. during nighttime). A pre-calculation should ensure a flux contribution from the area of interest of at least $90 \%$ ('high quality' according to e.g. Göckede et al., 2004) also under stable conditions for at least $50 \%$ of the time to ensure appropriate data coverage for different wind directions and varying weather conditions.

\section{Site and system dependent specific recommendations}

We prescribe recommendations by Munger et al. (2012) for the determination of the tower/measurement height $\left(h_{\mathrm{m}}\right)$, adjusted to give more flexibility due to real-world limitations such as restricted fetch conditions. The height above the canopy of the measuring system must be identified with the centre of the sonic anemometer path and its value depends on the canopy height $\left(h_{c}\right)$ of the ecosystem of interest. The canopy height value used to establish $h_{m}$ does not need to be particularly accurate: the average expected height of the dominant canopy layer is considered compliant. When measurements are performed too close to the ground or canopy to capture turbulent transport, this will result in anomalies in the shape of the spectral peak, which can be detected as suggested by Burba (2013). In this case, flux values may be biased by local effects and the representativeness for the investigated surface may be in doubt. 
For low surface heights such as grasslands, croplands and shrublands with a mean canopy height $\left(h_{c}\right)$ below $1.75 \mathrm{~m}$, $h_{m}$ must be comprised between $h_{m}=1.67 h_{c}$ and $h_{m}=6 h_{c}$. For forested or more structurally complex ecosystems, $h_{m}$ should be between $h_{m}=1.67 h_{c}$ and $h_{m}=2 h_{c}$. Anyhow, $h_{m}$ cannot be lower than $2 \mathrm{~m}$, and must always be discussed and agreed with the ETC, especially when a trade-off is needed (e.g. very tall canopies).

For croplands, grasslands and plantations with a fastchanging canopy height and stations with fast-changing snow cover heights, the tower design has to allow for changing measurement heights, either by changing the tower height (e.g. telescopic mast) or by moving the sensors, to ensure the same source area over time. Measurement height should be changed such that $h_{m}-0.67 h_{c}=$ const $\pm 10 \%$, but at most every second week during the vegetation period or during the snow pack season, respectively. Assuming a bare soil at the beginning of the vegetation cycle and a $h_{m}=2 \mathrm{~m}$, no changes are needed until $h_{c}$ reaches $1.2 \mathrm{~m}$. However it is recommended to start raising $h_{m}$ before the vegetation reaches $1.2 \mathrm{~m}$ (e.g. around 0.5-0.8 $\mathrm{m})$ and then keep $h_{m}-$ $0.67 h_{c}$ constant. Changing surface heights (due to growth and snow pack) as well as changing measurement heights must be documented via the ICOS BADM system as this has to be considered in the post-processing.

These recommendations reflect the experiences from field studies and will guarantee the quality that is achievable in the field over homogeneous surfaces. How large the homogeneous surface must extend around the tower, i.e. the fetch requirement for a surface representative measurement at $h_{\mathrm{m}}$, needs to be estimated prior to installation with footprint models and micrometeorological field data if available (e.g. Kljun et al., 2015) and section on spatial representativeness.

\section{Instrument installation on booms}

Eddy covariance and radiation instrumentation have to be installed away from the main tower on booms to minimize the direct effect of the tower structure on the mean airflow and reflection effects on the measured radiation.

The amount of instrumentation located in the vicinity of the EC turbulence measurements has to be reduced to a necessary minimum needed for corrections of EC data and their interpretation. This includes the incoming and outgoing short- and longwave radiation (typically measured with a four-component net radiometer), as well as diffuse and direct photosynthetic active radiation as described in the related paper of this issue about radiation measurements. Furthermore, air temperature, moisture, and air pressure are needed for precise correction of the measured fluxes, and have to be located within a vertical distance of about $0.5 \mathrm{~m}$ from the flux instrumentation. As a reference for the carbon dioxide- and water vapour mixing ratios measured by the
EC infrared gas analyser (IRGA), the mixing ratios have also to be measured at the same height by one individual inlet of the profile system.

The flow distortion around the 3D sonic anemometer should be minimized as much as practically possible. The remaining unavoidable distortion by the other instruments, cables, supporting arms has to be carefully documented. The supporting boom for the sonic anemometer together with inlets for gas analysis with the IRGA has to be directed into the prevailing wind direction (considering local circulations, day-night, and land-sea breeze) to maximize exposure time for the wind blowing from the desired land cover type. More than one prevailing wind direction has to be considered by an optimized arrangement of the sonic boom. Except for very strong slopes, the sonic anemometer has to be oriented horizontally. Within these positioning priorities for flux instrumentation, radiation sensors should be directed to the south (in the northern hemisphere) to avoid shading effects of the tower itself. In case of a conflict with prevailing winds from the south, the higher priority has to be given to the EC instrumentation. It is imperative that no other sensors or ancillary equipment shall be mounted on the boom containing the 3D sonic anemometer and the IRGA, nor shall these be placed within a horizontal distance of $1 \mathrm{~m}$ from the center of the anemometer.

The 3D sonic anemometer measures a vertical wind vector, a very small component of the overall large mean airflow, which is then used directly for computing the fluxes, corrections, and QA/QC (quality assurance and quality control) parameters, respectively. So the anemometer (see below for details) has to be mounted in a way to minimize any potential distortion. It should be placed at the end of the boom containing the IRGA head, facing away from the tower structure. To minimize cross-talk error, the center of the (virtual) sphere that encloses the IRGA inlet funnel (see below for details) has to be located in an area between the two vertical sonic arms and between the horizontal boom and the lower transducer (Fig. 1). The relative position of the tube inlet and the sonic path is setting a lower limit on the system time response. A simple parameterization of the transfer function describing the effect of lateral separation has been proposed by Moore (1986). It suggests that the EC system cut-off frequency (i.e., the frequency at which original fluctuations are reduced by a factor of 2) mainly depends on the lateral separation distance between sensors and on wind velocity. A more detailed analysis has been proposed by Horst and Lenschow (2009) who showed that this frequency depends on wind direction, stability conditions and would not be equivalent for vertical or horizontal separation (see also Kristensen et al., 1997).

However, the simple approach by Moore (1986) is sufficient for providing an order of magnitude of maximum available frequencies and it shows that separation distances lower than $15 \mathrm{~cm}$ are sufficient to achieve cut off frequencies higher than $5 \mathrm{~Hz}$ for most wind velocity conditions. 


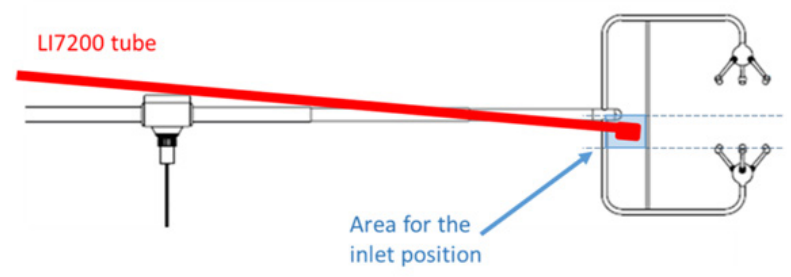

Fig. 1. Scheme of LI-7200 gas analyser tube and inlet with GillHS sonic anemometer. The rain cap of the GA must be placed in the light blue area as shown in the scheme, between the two vertical arms and between the sonic boom and the lower transducers (picture by Dario Papale, according to 'Instructions for Turbulent Flux Measurements of $\mathrm{CO}_{2}$, Energy and Momentum' provided by the ETC).

This constraint may be as important as those imposed by the gas sampling system (GSS). IRGA tube inlet positioning should thus result in a compromise: the gas sampling point should be as close as possible to the sonic anemometer measurement volume, but it should minimally distort the flow inside this volume (Fig. 1). Thus, it is recommended that the tube inlet is as compact as possible.

Booms have to be stable enough such as to support the instrumentation. This may require an additional supporting structure for the IRGA-tubing to avoid torque and oscillations of the tubing. Specific requirements for instrument placement on booms are listed in the appendix A1.

\section{ULTRASONIC ANEMOMETRY IN ICOS EC-FLUX SYSTEMS}

Fast-response three-dimensional wind and air temperature measurements are required for the EC technique and carried out with ultrasonic anemometers. Ultrasonic anemometry includes no moving parts, and electronic delays are small and well characterized. The time constant is small enough to allow high sampling frequencies with a singlesample interval (firing period) that is usually shorter than the Kolmogorov time-scale (for HS-100 individual firing interval is $10^{-2} \mathrm{~s}$ ). In addition, ultrasonic anemometers can be operated continuously over long periods of time ( $>$ year) and can withstand, or recover from, severe weather conditions. The general principles of sonic anemometry are described sufficiently well in the manufacturers' manuals and in several relevant publications (Aubinet et al., 2012; Burba, 2013; Foken, 2008; Lee et al., 2004).

Recent instrument performance reviews of commercially available $3 \mathrm{D}$ ultrasonic anemometers (henceforth: sonic anemometers) have not been able to identify a single perfect anemometer for scientific applications in a wide variety of ecosystems as covered within ICOS (Christen et al., 2000; El-Madany et al., 2013; Mauder et al., 2007; Mauder and Zeeman, 2018; Vogt and Feigenwinter, 2011; Vogt et al., 1997). Instead, the currently available models are seen to have specific advantages and disadvantages (Frank et al.,
2016; Huq et al., 2017). Nonetheless, ICOS policy requires a selection of a single standard sonic anemometer at least during the initial phase of ICOS.

The horizontally symmetrical research-grade ultrasonic anemometer, model HS-100 (Gill Instruments Ltd, Lymington, UK) was chosen as the initial ICOS-Ecosystem standard instrument (note: the HS-50 model differs from the HS-100 only in the maximum sampling rate and may also be used). The HS-100 is a non-orthogonal 3-axis anemometer that features a horizontal head design and stainless steel construction, mounted on a short horizontal arm ( $c a .1 \mathrm{~m}$ length). The head of the anemometer contains a built-in inclinometer (rated accuracy of $\pm 0.3^{\circ}$ from $-10^{\circ}$ to $+10^{\circ}$ of inclination). A full description of the instrument specifications is available from the manufacturer at: http:// www.gillinstruments.com/data/datasheets/HS-100-WebDatasheet.pdf (GILL, 2017).

Neither the Gill HS-100 instrument, nor any other currently available commercial model, are seen as ideal for the broad range of environmental conditions expected at ICOS stations (i.e., from Mediterranean and even tropical stations to sub-arctic climates, high winds, all types of precipitation including hoar-frost and riming; exposure to a range of UV radiation or ozone concentrations). Especially ice coating may lead to high data losses during winter in cold regions. The EC Working Group of the ICOS-Ecosystems MSA together with the ETC recommends that: (i) heating (possibly by application of heating tape) may be added to the HS anemometer when absolutely required; (ii) nn additional sonic anemometer has to be used, with data processed by the station team, and sent to the ETC.

In cases when heating is applied to the sensor arms, the instrument needs to be recalibrated with the heating device installed. If the standard system should fail for substantial periods of time, the additional EC system may be used to fill the data gaps. Such an arrangement satisfies the requirements for a network-wide standard, but also facilitates the identification and characterization of systematic and random uncertainties, and serves as the experimental basis for future improvements of EC technology and future developments of the ICOS standards.

If an alternative EC system is used in addition to the ICOS EC system at a particular station, care must be taken to distance it from the standard system far enough to avoid flow distortion, cross-talk or aerodynamic wake effects, but close enough for the two systems to have identical flux footprints.

\section{HIGH-FREQUENCY CONCENTRATIONS OF $\mathrm{CO}_{2}$ AND $\mathrm{H}_{2} \mathrm{O}$}

High-frequency $\mathrm{CO}_{2}$ and $\mathrm{H}_{2} \mathrm{O}$ concentrations are measured with a non-dispersive infrared (NDIR) absorption analyser (commonly referred to as infrared gas analyser - IRGA). The radiation source used in IRGAs is a spectrally broadband filament source. An optical filter is used 
to isolate a range of wavelengths corresponding to an absorption band of the gas being measured. In addition to the absorption band, dual-wavelength single-path IRGAs use a reference band where the radiation is not absorbed by any component in the sampling path. The transmittance is computed as the ratio of optical power transmitted through the gas to the detector in the sample band where radiation is absorbed, divided by optical power transmitted through the gas in the reference band where radiation is not absorbed (Fratini et al., 2014; Munger et al., 2012; Welles and McDermitt, 2005).

IRGAs can be designed for either open-, enclosed-, or closed-path configurations. A closed-path analyser has an internal sample cell that is flushed with the sample air, while open-path sensors sampling cell is located in the ambient air in situ. Each of these two traditional configurations has its advantages and weaknesses listed by Burba et al. (2010). The more recent enclosed design tends to maximize advantages and minimize weaknesses of open- and closed-path designs. The enclosed analyser is fundamentally based on the open-path system and it is therefore weatherproof, but it uses a closed-path sampling configuration similar to closedpath devices, which prevents data loss during precipitation. The instrument is designed to be used with a short intake tube, which minimizes frequency losses in comparison with traditional closed-path design. The remaining losses nonetheless remain significant and still require spectral corrections (Fratini et al., 2012). The design also allows to minimize the need for density corrections (Webb et al., 1980) due to the high-frequency measurements of the air temperature and pressure inside the sampling cell which are precisely aligned with the measurements of $\mathrm{CO}_{2}$ and $\mathrm{H}_{2} \mathrm{O}$ concentration, both electronically and in terms of sampled flow (Burba et al., 2010, 2012; Furtaw et al., 2012a, $2012 \mathrm{~b}$ ). As a result of these advantages, the enclosed design was selected as the standard design during the initial phase for the ICOS network.

Field tests and analysis started by ICOS in 2010 used the original version of the enclosed IRGA (e.g., LI-7200, LI-COR Biosciences, Lincoln, USA), the only one available at that time, and continued for the following 3 years using both original and updated versions of the instrument. As a result of these tests, the most recent version of LI-7200 was chosen as the initial ICOS-Ecosystem standard instrument for high-frequency $\mathrm{CO}_{2}$ and $\mathrm{H}_{2} \mathrm{O}$ flux measurements. The analyser protocol summarized here has been developed based on the tests and specifications determined by a combined working group from ICOS MSA, NEON and external experts to assure inter-comparability.

In order to correctly compute fluxes using EC approach, the trace gas concentrations measured by the analysers must be converted into dry mole fractions. Usually, the conversion must be done using high frequency measurements, before covariance computation. Alternatively, the effects of air density fluctuations can be accounted for dur- ing post-processing using density corrections (Webb et al., 1980). When temperature and pressure of the sampled air are measured at a fast rate across the sampling cell and precisely aligned with the water vapor and gas concentrations, the conversion may be done on high-frequency data either inside the instrument (e.g., LI-7200) or during the postprocessing stage before the covariance computation (Burba et al., 2012; Ibrom et al., 2007a,b; Nakai et al., 2011). If the 'instantaneous' conversion is not used, applying the density corrections to the closed-path or enclosed instrument requires some care. Only the formula employing $w^{\prime} T^{\prime}$ (with $T^{\prime}$, the fluctuation of cell temperature aligned with $\mathrm{CO}_{2}$ time series) may be used, and not the one referring to sensible heat flux measured at the ecosystem level (Eq. (44) in Webb et al., 1980). It is recommended to store all intermediate variables in either of the two approaches to be able to check measurement quality at a later time (see section on data acquisition and appendix A5).

Another important feature of closed-path and enclosed IRGAs is the pumping system that transports air from the sampling point to the analyser cell. Cell air renewal rate and air flow through the pumping system are often the main limitations on the system response time. The positioning of the air sampling tube inlet, dimensions and material of the tube, type of filters or flow rates, must be chosen as a trade-off between several, sometimes concurrent constraints explained below. Further details on this are provided in Aubinet et al. (2016) and Metzger et al. (2016).

\section{High-resolution IRGA variables}

The scalar intensity of an atmospheric constituent $s$ may be described by several variables (ISO, 2009): mass concentration $\left(\rho_{\mathrm{s}}, \mathrm{kg} \mathrm{m}^{-3}\right)$ or concentration $\left(c_{s}, \mathrm{~mol} \mathrm{~m}^{-3}\right)$ represents the mass or the amount of substance of $s$ per volume of air, respectively. The mass fraction $\left(\mathrm{kg} \mathrm{kg}^{-1}\right)$ is the ratio of the mass of $\mathrm{s}$ divided by the mass of the mixture. The mole fraction $\left(\chi_{s}, \mathrm{~mol} \mathrm{~mol}^{-1}\right)$ is the ratio of the amount of substance of $s$ divided by the total amount of substance of the mixture (also equal to the ratio of the constituent partial pressure to the total pressure), the dry mole fraction $\left(\chi_{s, m}\right.$, mol mol$\left.{ }^{-1}\right)$ is the ratio of the amount of substance of $s$ to that of dry air. These variables are related to temperature, pressure and water vapor content via the ideal gas and the Dalton laws. Conversion factors are given in Table 1.

Among these variables, only the dry mole fraction is a conserved quantity of the substance in the presence of changing temperature, pressure and water vapour content (Kowalski and Serrano-Ortiz, 2007). However, infrared gas analysers measure substance amount in the volume that is not a conserved quantity in these conditions. Therefore, concentration variations may appear in the absence of production, absorption or transport of the component. For this reason, the turbulent flux, that is representative of the ecosystem source/sink intensity, is the covariance of the 
Table 1. Conversion factors between variables describing the scalar intensity of an atmospheric constituent

\begin{tabular}{|c|c|c|c|}
\hline Conversion factor & $\begin{array}{l}\text { Dry mole fraction, } \\
\qquad \chi_{s}=\end{array}$ & $\begin{array}{l}\text { Concentration, } \\
\qquad C_{s}=\end{array}$ & $\begin{array}{c}\text { Mass concentration, } \\
\rho_{s}=\end{array}$ \\
\hline $\begin{array}{l}\text { Dry mole fraction } \\
\qquad \chi_{s} \mathrm{X}\end{array}$ & 1 & $\frac{p_{a}-p_{v}}{R T_{a}}$ & $\frac{m_{s}\left(p_{a}-p_{v}\right)}{R T_{a}}$ \\
\hline $\begin{array}{c}\text { Concentration } \\
c_{s} \mathrm{X}\end{array}$ & $\frac{R T_{a}}{p_{a}-p_{v}}$ & 1 & $m_{s}$ \\
\hline $\begin{array}{l}\text { Mass concentration } \\
\qquad \rho_{s} \mathrm{X}\end{array}$ & $\frac{R T_{a}}{m_{s}\left(p_{a}-p_{v}\right)}$ & $\frac{1}{m_{s}}$ & 1 \\
\hline
\end{tabular}

The variable in the column header is obtained by multiplying the variable in the line header by the factor given in the Table. $p_{a}$ : atmospheric pressure $(\mathrm{Pa}) ; p_{v}$ : water vapour pressure $(\mathrm{Pa}) ; R$ : gas constant $\left(8.314 \mathrm{~J} \mathrm{~K}^{-1} \mathrm{~mol}^{-1}\right) ; T_{a}$ : air temperature $(\mathrm{K}) ; m_{s}$ : scalar molar mass $\left(\mathrm{kg} \mathrm{mol}^{-1}\right)$.

vertical wind velocity and the component dry mole fraction. All variables available from the analyser that have to be acquired are listed in Table A1.

Important issues to be considered:

Spectral attenuation:

Although the LI-7200 is able to capture turbulence up to $20 \mathrm{~Hz}$, high-frequency fluctuations may be reduced due to the system setup. Most important causes of high-frequency attenuation are the air mixing through the gas sampling system (GSS) and the separation between the IRGA sampling point and the sonic anemometer (Aubinet et al., 2016; Metzger et al., 2016). It is crucial that the spectral attenuation of the instrument and the sampling system as a whole is measurable and kept in an acceptable range. This is particularly important for $\mathrm{H}_{2} \mathrm{O}$, which strongly interacts with the tube walls and filter surfaces, and for which the level of the interaction depends on relative humidity, tube age and wall contamination (Fratini et al., 2012; Ibrom et al., 2007a,b; Leuning and Judd, 1996; Mammarella et al., 2009).

Gas sampling issues:

The gas sampling system (GSS) transports the air from the sampling point to the analyser cell. In order to guarantee high-quality measurements, the GSS has to meet several constraints, which are sometimes conflicting:

- minimize high-frequency spectral attenuation of concentration measurement

- maximize attenuation of temperature fluctuations

- minimize pressure drop in the measurement cell

- minimize cell contaminations

- minimize pump-induced pressure fluctuations

- minimize power consumption

- minimize airflow perturbation at the sampling point

- minimize temperature fluctuations caused by direct irradiation on the IRGA.
To make this possible, several parameters must be adjusted such as the characteristics of the pumping system (general layout, pump type, flow controller, buffer), the tube (material, shape, heating), the filter (material, type, heating) as well as the system dimensions (tube diameter and length, volume flow, filter choice).

\section{General layout of the gas sampling system}

The system consists of the inlet rain cap, filter, sampling tube, IRGA, potential buffer, flow controller and the flow module or a pump whose output is returned to the open air (Fig. 2). The elements upstream from the IRGA cause a pressure drop related to the flow rate, filter and rain cap characteristics, and tube dimensions. Per specifications of the high-speed differential pressure sensor used in LI-7200, this pressure drop must not exceed $10 \mathrm{kPa}$. Downstream of the analyser, the air passes through a buffer that dampens pump-induced fluctuations, a flow controller that maintains flow at a fixed value and, finally, the pump. Alternatively, buffer, flow controller and the pump can be replaced by an integrated flow module specifically designed for the LI-7200 (LI 7200-101). However, per manufacturer specification this system cannot provide a pressure pull larger than $3.5 \mathrm{kPa}$, so the flow restrictions (e.g., filter graining, filter clogging and tube length) have to be kept at acceptable levels in order to maintain a desirable flow rate (see also Metzger et al. (2016), Aubinet et al. (2016)). A stronger pump might be necessary to avoid the necessity of frequent filter changes in polluted areas.

\section{Pump:}

The pump should provide a flow rate that is higher than $9.61 \mathrm{~min}^{-1}$ in order to maintain 10 cell renewals per second $(10 \mathrm{~Hz})$. Pump capacity must significantly exceed the nominal flow rate selected for the system to lengthen pump longevity. Robustness and durability of the pump are fundamental. Brushless pumps have been identified as 


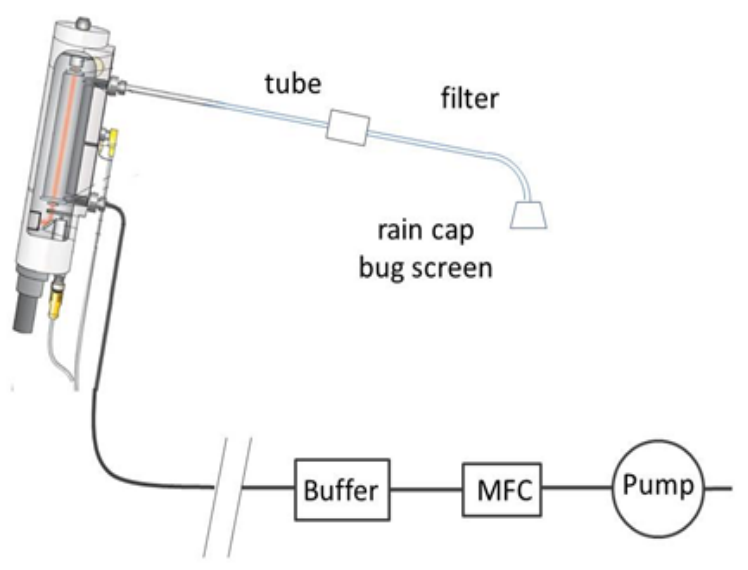

Fig. 2. General layout of the gas sampling system. Image combined by Marc Aubinet. The LI-7200 head scheme was drawn by Jon Gooding and is a courtesy of LI-COR Biosciences provided by George Burba.

a suitable option for continuous operation due to their reliable endurance, providing a flow rate of around $301 \mathrm{~min}^{-1}$ for thousands of hours.

A water collector should be placed between the head of the analyser and the pump or flow controller in order to avoid flow controller and pump damage by condensation. The pump should further be ventilated to avoid overheating or condensation inside the pump box.

Flow controller:

The system must be completed by a flow controller, compatible with the pump, which should be able to maintain the required flow $\left(10-151 \mathrm{~min}^{-1}\right)$. The need for a thermostat should be considered to prevent damage when the flow is off. Indeed, many flow controllers become extremely hot and might break in case of pump stopping.

\section{Buffer:}

The buffer is necessary to attenuate the pressure fluctuation that could be induced by the pump. It is simply a dead volume (about 5 l) placed between the analyser and the flow controller. Spherical buffers withstand more pressure fluctuations than volumes extended along the direction of the sampling flow. In and out ports should be placed in the order that the flow passes through the buffer. When the integrated flow module (LI 7200-101) is used instead of the pump, no buffer is needed.

\section{LI-7200 Flow module:}

The LI-7200-101 flow module consists of an integrated system including a fan blower and a flow controller. It provides a constant programmable flow rate between 10 and $18 \mathrm{sl} \mathrm{min}^{-1}$, under pressure drops between 0.5 and $3.5 \mathrm{kPa}$. As the system does not produce appreciable pulsations, no buffer is needed. The pump requires about $13 \mathrm{~W}$ power during normal operation (around 0.5-1 $\mathrm{kPa}$ pressure drop) but this could increase up to $35 \mathrm{~W}$ under extreme clogging of the filter. The capacity of the LI7200-101 module to produce a sufficient flow rate to ensure the cell refreshment at $5-10 \mathrm{~Hz}$ frequency in presence of filters is discussed in the section on 'General system dimensioning'.

Tube:

In ICOS, only one specific tube dimensioning is accepted: the tube has to have an inner diameter of $5.33 \mathrm{~mm}$ and a length of $71.1 \mathrm{~cm}$ which is supplied with the packages 7200-040 and 7200-050 (LI-COR Biosciences, Lincoln, Nebraska). This tube length represents the best trade-off between avoiding flow perturbation in the sonic sampling volume, minimizing temperature fluctuations and high-frequency concentration losses in the tube. The tube material has to be as inert as possible with respect to $\mathrm{CO}_{2}$ and water vapour. Stainless steel with a smooth inner surface is recommended. Turns and dead volumes can create vortices contributing to high-frequency losses and must be avoided.

Tubing must be heated and insulated in order to prevent water condensation and sorption on the tube surfaces which could strongly affect the cut-off frequency for the $\mathrm{H}_{2} \mathrm{O}$ measurements. The heating power shall be chosen such that the combined effect of pressure drop and the heating reduce the relative humidity in the IRGA sampling cell during sampling mode to $\leq 60 \%$ for ambient dew points $\leq 30^{\circ} \mathrm{C}$. An additional constraint is that the temperature difference between the cell inlet and outlet should not exceed $5^{\circ} \mathrm{C}$. A heating power of $4 \mathrm{~W} \mathrm{~m}^{-1}$ allows the system to meet these requirements (Metzger et al., 2016).

Filter:

The intake filter is required in polluted locations to avoid rapid cell contamination and premature destruction, by dust particles, of the in-flow fast response thermocouples located at the cell inlet and outlet. The contamination deposition on the cell windows can potentially introduce biases in gas measurements and calculated fluxes (Fratini et al., 2014), and in the absence of the intake filter, would require more frequent cleaning. On the other hand, filters can perturb the air flow near the anemometer, cause additional pressure drop in the cell, and may attenuate measured gas concentrations. The latter effect is becoming more important when the filters become dirty or wet.

The choice of a filter aims at minimizing these drawbacks. The following criteria for determining filter characteristics were considered when selecting the Swagelok ${ }^{\circledR}$ FW stainless steel filter with $2 \mu \mathrm{m}$ pore diameter as compliant:

- Compromise between porosity and pressure drop: The pressure drop is inversely related to pore diameter and filter material. The pressure drop should be as small as possible in order to limit power consumption, avoid the necessity of using powerful pumps and allow internal IRGA post-processing for pressure compensation. The optimal pore size should be adapted at each station, according to 
its degree of pollution but has to be reconciled with ETC. After careful testing and selection (Aubinet et al., 2016; Metzger et al., 2016) the $2 \mu \mathrm{m}$ pore diameter was recommended as a good compromise between pressure drop and pollution filtering.

- Compromise between pressure drop and filter volume: At a given porosity, filters with large exchange surfaces would probably provoke lower pressure drops. However, as they constitute dead volumes, they could affect highfrequency fluctuations. Small volume filters are therefore generally recommended.

- Filter material: The filter material should be as inert as possible with respect to $\mathrm{CO}_{2}$ and $\mathrm{H}_{2} \mathrm{O}$. Stainless steel and Teflon filters fulfil these requirements. However, Teflon filters have several times the flow resistance of a metal mesh filter with similar mesh size. In addition, while a metal mesh filter has a single and defined pore size, each Teflon filter comprises a distribution of pores of different sizes, with the nominal pore size falling somewhere within this distribution (Metzger et al., 2016).

- Ease of use: As the filter must be changed regularly, and sometimes in difficult conditions on top of high towers, practicability is an important criterion. Digitally monitoring the flow rate and cell pressure drop helps to detect the need for changing the filter.

- Filter position: the filter is positioned after about half of the tube section that is heated, thus an additional heating is not required. If small-volume filters are used in such a position, the filter-related perturbation of the airflow in the anemometer sampling volume is negligible.

Rain cap - bug screen:

It is necessary to install a rain cap and a bug screen at the tube entrance to avoid filter clogging by raindrops, snowflakes, insects and coarse dust particles. The size of the cap must be limited in order to not perturb winds near the sonic anemometer path. Turns, dead volumes, connectors and necks have to be avoided, even when very short, because they can cause vortices and create mixing volumes leading to high-frequency losses. Only the rain cap 9972-072 (LI-COR Biosciences, Lincoln, Nebraska) is accepted by the ETC. Both rain cap and bug screen need to be cleaned regularly.

\section{General system dimensioning:}

A summary of all constraints on the filter type, tube dimensions and flow rate is provided in the appendix A3. All constraints are expressed in terms of tube dimensions (diameter and length), volume flow rate and filter characteristics. Independently, experiments were developed in order to obtain filter characteristics (Aubinet et al., 2016; Metzger et al., 2016) with respect to the relation between flow rate and pressure drop or cut-off frequency.

\section{Analyser calibration and maintenance}

Instrument calibration by the factory, field calibrations and maintenance of the GSS have to be performed as described in the respective ecosystem instructions (http:// www.icos-etc.eu/icos/documents/instructions). For each factory calibration, the manufacturer has to provide the certificate including new polynomial coefficients based on calibrations performed for each individual gas analyser over a range of gas concentrations for each of multiple temperature levels covering the ambient measurement range. In order to reduce data losses during critical time periods, the factory calibration should be scheduled outside the growing season, whenever possible.

\section{DATA ACQUISITION}

In order to be able to calculate EC fluxes, one needs to quantify the turbulent fluctuations of both the vertical wind velocity and air temperature or the scalar quantity of interest. In addition to the components directly needed for flux calculations, all available raw data and diagnostics have to be acquired and stored to ensure high data quality.

\section{Hardware}

The sonic anemometer HS-100/50, gas analyser LI-7200 including the analyser interface unit (AIU) LI-7550, the device logging fast data streams from EC instrumentation, and the device logging slower data streams from the complementary meteorological, radiation and soil data are the principal components of ICOS EC stations. It is vital for correct EC flux computation that the analyser and the anemometer are set up in a way to either have synchronized clocks (much preferred) or at least to have synchronized precisely aligned data sets. In addition, the diagnostics from the sonic anemometer and the gas analyser have to be collected and aligned with the wind components, sonic temperature, gas concentrations, fast air temperature and pressure in the sampling cell, etc. It is not a trivial task because all of these components have their own instrument clocks drifting at different rates and directions, and all use their own different communication protocols.

This requires a fully digital data acquisition system able to synchronize and align different clocks and data streams coming via multiple communication protocols. The main hurdle with such a data acquisition is to assure precise clock synchronization between the three instruments: IRGA, sonic anemometer and data acquisition device itself; without the risk of introducing jitter, undersampling, lag times, and other issues in signals from these devices. Otherwise, fluxes can be underestimated or severely biased. The device that collects the slow complementary data does not have to be as tightly synchronized to the analyser and anemometer, but should still be well in-synch. 
There are several options available for doing this using a variety of loggers, computers, and/or new acquisition devices. Each configuration has specific advantages and disadvantages, but all must have clocks synchronized with the standard time (atomic clock) of the respective time zone or UTC via GPS, radio clocks (e.g. DCF77) or internet connection, and all must provide the possibility for remote connection by land-line or cellular network.

Three possible options exist aiming to fulfil the fully digital $10 / 20 \mathrm{~Hz}$ data acquisition requirements, even though none of them is fully tested and confirmed at the stage of submitting this document and other systems might arise:

- Acquisition using a traditional data logger:

a. sonic data (2 status bytes, wind components, sonic temperature) via $\mathrm{RS} 232 / \mathrm{RS} 422 / \mathrm{RS} 485$;

b. gas analyser data (e.g. mixing ratios, densities and absorptance of $\mathrm{CO}_{2}$ and $\mathrm{H}_{2} \mathrm{O}$, AGC, cell pressure, $\mathrm{T}_{\mathrm{in}}$, $\mathrm{T}_{\text {out }}$, block temperature, diagnostic value) via SDM (so far SDM is a closed proprietary protocol by Campbell ${ }^{\circledR}$ Scientific), RS232/RS422/RS485 or Ethernet;

c. low-frequency data from LI-7200 flow module via RS232.

- Acquisition with a conventional computer which can be adapted to collect multiple streams of high-frequency EC data:

a. sonic data ( 2 status bytes, wind components, sonic temperature) via RS232/RS422/RS485;

b.gas analyser data (e.g. mixing ratios, densities and absorptance of $\mathrm{CO}_{2}$ and $\mathrm{H}_{2} \mathrm{O}, \mathrm{AGC}$, cell pressure, $\mathrm{T}_{\mathrm{in}}$, $\mathrm{T}_{\text {out }}$, block temperature, diagnostic value as well as lowfrequency data from LI-7200 flow module) via RS232 or Ethernet TCP-IP.

- Acquisition with a weatherized flux computer (SmartFlux 2/3, LI-COR) specifically designed for highspeed clock synchronization of the EC data acquisition (Ediger and Riensche, 2017):

a. sonic data (2 status bytes, wind components, sonic temperature) via RS232/RS422/RS485;

b. gas analyser data (e.g. mixing ratios, densities and absorptance of $\mathrm{CO}_{2}$ and $\mathrm{H}_{2} \mathrm{O}, \mathrm{AGC}$, cell pressure, $\mathrm{T}_{\mathrm{in}}$, $\mathrm{T}_{\text {out }}$, block temperature, diagnostic value as well as lowfrequency data from LI-7200 flow module) via Ethernet PTP.

In addition, temperature and humidity from slow sensors may be logged by the same devices. Data streams can be merged online and written together to the same file, prefixed by a common timestamp. Time stamps can be set by the data logger or the computer device.

Synchronized data streams have to be guaranteed in any of the suggested acquisition types to avoid unrecognized underestimations of fluxes and new developments have to be tested. The advantages of a datalogger-based acquisition are mainly the low power consumption and historical outdoor durability. The disadvantages include: (i) possible inability to synchronize clocks from the three devices using public and open protocols, specifically the inability to cor- rectly synchronize data streams from the Gill HS-50/100 (via serial) with the LI-COR LI-7200 (via TCP Ethernet); (ii) inability to conduct full flux processing; and (iii) lack of data visualization.

A conventional computer may be used for data collection, on-line flux processing and additional data storage. It has the superior processing power and can easily push data files to the ICOS Carbon Portal server, including handling communication errors. If equipped with a monitor, it can also be used for graphic presentation of raw and processed data. Several other advantages include phenocam control, communication with biomet loggers, networklevel visualizations of live data via a web browser, etc. The disadvantages include: (i) the relatively high costs of purchasing, installing, protecting, and maintaining a $\mathrm{PC}$ at a field site, (ii) the need of grid power typically required to operate the computer; (iii) the practical complexity of properly timestamping the incoming HS-50/100 serial data so it can be aligned and synchronized with the LI-7200 data coming via the Ethernet. The latter is technically very complex and may require significant testing at a specific station. It is highly recommended to take precautionary measures in case the power supply fails. Computers and most data acquisition software can be configured to resume their work and data logging automatically after a power outage so that no operator's action is required. In addition, the installation of an uninterruptible power supply (UPS) can help to bridge short power outages by providing emergency power to the computer as well as to the EC instrumentation, effectively helping to avoid an immediate restart of the system and therefore data loss. UPS units are also capable of correcting common utility power problems like voltage spikes, which otherwise might interfere with data acquisition and reduce data quality. An email alert can be sent to the user to inform about power problems.

\section{ADDITIONAL MEASUREMENTS NEEDED TO ACHIEVE HIGH-QUALITY EC FLUXES: AIR TEMPERATURE, HUMIDITY AND AIR PRESSURE}

In order to perform corrections in the post-processing procedures, it is necessary to measure air temperature and air humidity as well as air pressure in the same height as the EC data are acquired. Such a correction is the so-called Schotanus or SND-correction (Schotanus et al., 1983) that considers the difference in measured sonic (acoustic) temperature compared to actual air temperature. It is most important that air temperature and humidity are measured at the same height as the gas concentrations and wind speed components for EC calculations. But these instruments should be far enough to avoid flow distortion. Above tall vegetation, carbon dioxide and water vapour concentrations have to be measured along the tower to account for storage processes below the measurement height of the EC system. 


\section{Air temperature}

The air temperature is defined as 'the temperature indicated by a thermometer exposed to the air in a place sheltered from direct solar radiation' (WMO, 2008, 2014).

Units, ranges and ecosystems:

The physical unit of thermodynamic temperature $(T)$ is Kelvin $(\mathrm{K})$. The unit Kelvin is defined as the fraction $1 / 273.16$ of the triple point of water. For most meteorological purposes temperature measurements are expressed in Celsius degree $\left({ }^{\circ} \mathrm{C}\right)$, derived from Kelvin by the linear relation $t=T-273.16$.

The range of values requested by the World Meteorological Organization (WMO) for air temperature measurements is -80 to $+60^{\circ} \mathrm{C}$. Considering the whole range of climates and ecosystems that could be monitored within the ICOS network this range can be reduced, also to reduce technical and economical requirements. Maintaining linearity and precision levels for proper measurements along this whole range would be extremely difficult if not impossible in practice. An acceptable measurement range for ICOS stations is thus -55 to $+55^{\circ} \mathrm{C}$.

Technical requirements:

The physical quantity itself requires specific arrangements for the sensors to avoid interferences mainly from radiation and heat dissipation due to various elements such as e.g. precipitation, fog, deposition or bodies with different thermal capacity in close proximity. Generally, this problem is mentioned as radiation error and is a big concern in the air temperature measurement because it is difficult to quantify (Foken, 2008). Here, we consider only measurements of air temperature representative of the atmospheric surface layer and roughness sub-layer in the proximity of the ecosystem canopy top, i.e. the value that must be used in conjunction with flux measurements. The air temperature measurement method for heat storage estimation in canopy space follows the same principles when measurement heights are fitted to the storage measurements for $\mathrm{CO}_{2}$ and $\mathrm{H}_{2} \mathrm{O}$.

The instrument for measurements of air temperature in close vicinity of the EC measurements has to provide characteristics similar to WMO standards: accuracy and precision have to be high enough to allow a measurement uncertainty in the order of magnitude of $0.1 \mathrm{~K}$ in the range -40 to $+40^{\circ} \mathrm{C}$ and lower than $0.3 \mathrm{~K}$ outside this range, as stated by WMO (2014), and a response time in the range 20 to $40 \mathrm{~s}$ or lower (see appendix A6 for definitions of accuracy, precision and response time). Long-term stability and robustness under all weather conditions are required to avoid corrosion or other physical deformation in order to provide stability over a period of at least two years. However, these requirements are defined for ideal working conditions and it is not always possible to achieve these during routine field operations. As a consequence, also thermometers with an overall accuracy of $0.2 \mathrm{~K}$ in the measuring range -30 to $45^{\circ} \mathrm{C}$ can be accepted for ordinary measurements (WMO, 2014). For each thermometer normally the accuracy depends on temperature and the reference best accuracy value of $0.2 \mathrm{~K}$ is referred to the thermometer in ideal conditions after initial calibration from the factory. Accuracy variations in the measuring range can still be accepted up to a value of two times the reference value, i.e. $0.4 \mathrm{~K}$.

Variability in time and space:

Air temperature varies continuously with time according to interactions between daily radiation cycles, synoptic meteorological variations and changing surface properties. Site characteristics, trends and minimum and maximum values, together with other meaningful statistics, can be derived from previously collected datasets or from preexisting stations in proximity to the study site to evaluate range and time variations of this variable for the specific site. The time resolution of the air temperature measurements must allow detection of changes in the order of $0.033 \mathrm{~Hz}$ with a dense enough time series of samplings. It means that the step response time (A6 for definition) of the sensor selected for specified accuracy and precision levels must have an order of magnitude of $30 \mathrm{~s}$. Lower frequency variations, i.e. with periods ranging from a few hours to several years, can have amplitudes of several tens of Kelvin, depending on the climate and the microclimate of the specific site. For this, air temperature measurements generally do not bear significant challenges except for the risk of sensor drifts if not avoided by proper maintenance. However, the quantification of time resolution of the overall measurement system is not straightforward because of the thermal inertia of the sensor itself and, most importantly, the ventilated screen that has to be used to avoid radiation errors (see below). The overall delay induced by system response to air temperature fluctuation is generally not exactly determined. A sampling frequency of $0.033 \mathrm{~Hz}$ $(\mathrm{T}=30 \mathrm{~s})$ is enough to detect temporal variations of air.

Measurement method and instrument recommendations:

In combination with EC measurements, air temperature is required to be measured at the same height as the gas analyser and the sonic anemometer are placed. Main requirements are to avoid shadowing and any possible emission or absorption from surrounding elements. WMO requires a minimum distance of $1.5 \mathrm{~m}$ from all other structures and instruments and prescribes a minimum height of $2 \mathrm{~m}$, above the ground (WMO, 2008). This last requirement does not consider ecological characteristics of the surfaces of interest, in particular, canopy height and roughness length. Air temperature and air humidity measured in conjunction with EC measurements have to be installed without affecting each other and such as to avoid shadowing, thermal interaction and flow distortion. Basically, a good compromise has to be found for each site once the measurement height for the EC system has been defined. 

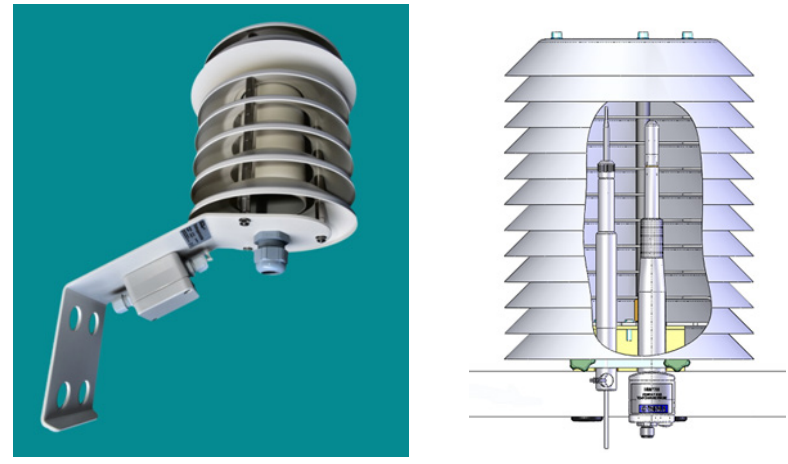

Fig. 3. Examples of radiation shields (left: meteoclima with forced ventilation according to ISO17714:2007 (https://fischerbarometer.de/meteoclima/de/index.php), image kindly provided by meteoclima, right: Vaisala DTR13 but with only natural ventilation, HMP155 Quick Reference Guide - M210913EN-C), image kindly provided by Vaisala.

Radiation from different sources can affect air temperature measurements, e.g. from sun, clouds, ground and object close to the sensor. Also, precipitation and condensation affect measurements. Moreover, deposition of dust, aerosols and any other material affects significantly response characteristics of the thermometers. Clean screens or shields are mandatory and must be considered part of an air temperature measuring system. Generally, the screens can be used as a physical support of the system (Fig. 3). They must allow for sufficient air circulation between sampling volume of the thermometer and the atmosphere, preventing from an imbalance between absorbed and dissipated heat. A comprehensive description of radiation shields types and uses is available on the WMO guide, together with specific literature references on this issue (ISO, 2007; Lacombe et al., 2011; WMO, 2008). In the framework of ICOS, a white screen (double cylinder) with forced ventilation $\left(5-7 \mathrm{~m} \mathrm{~s}^{-1}\right)$ is required to ensure proper air circulation. The screens for air temperature can also be used to host the air relative humidity.

According to the previously mentioned general description and rational, the use of electrical thermometry among those indicated by WMO is recommended because it provides reliable estimates of the temporal variation. Among the different electrical methods (electrical resistance thermometry, semiconductor thermometry, resistor thermometry) the recommended method for air temperature measurements is the resistance thermometry with platinum (Pt) thermistors (e.g. PT100 or PT1000, where 100 and 1000 indicate the resistivity in $\mathrm{Ohm}$ of the sensing element) because they both provide high level of metrological characteristics (accuracy, precision, sensitivity, step response time) at acceptable cost. Between thermistors, the platinum-based resistance thermometers are widely used due to their stability over time and because these resistances have a high-temperature coefficient, to provide high sensitivity of the device. Moreover, they have a good linearity in the typical measurement range.

\section{Recommended instruments:}

PT100 or PT1000 thermistors for air temperature (Accuracy: $\pm 0.1 \mathrm{~K}$ for the sensing probe, excluding screen and datalogging errors, precision: $\pm 0.1 \mathrm{~K}$, step response time: 20 s (WMO, 2008) are offered from various manufacturers. Calibration has to be provided from the producer with internationally recognized standard (e.g. NIST, BIPM/ JCGM (2008), BIPM/JCGM (2008), etc.) or through national metrology institutions.

\section{Air humidity}

According to WMO, the relative humidity $(R H)$ of the air is defined as 'the ratio (in percent) of the observed vapour pressure to the saturation vapour pressure with respect to water at the same temperature'. In contrast, specific air humidity is defined as "the ratio between the density of water vapour and the density of moist air", and dew point temperature $T_{D P}$ as 'the temperature at which moist air saturated with respect to water at a given pressure has a saturation mixing ratio equal to the given mixing ratio'. These quantities are particularly relevant because air relative humidity is mostly directly measured and connected with the other variables and can even be evaluated with higher precision as for example with a dew point mirror (see below).

Relative humidity is expressed in percentage values, being a ratio of two values of the same entities, i.e. vapour pressures. $R H$ shows an indifferent behaviour depending on both climatic and meteorological constraints. Therefore, time evolution does not have typical seasonal patterns as is the case for solar radiation or temperature. For each ecosystem and climate only maximum and minimum values can be stated. The maximum value is $100 \%$ during condensation conditions, while minimum values for all ecosystems, except hyper-arid systems, rarely drop below 10\%. A reasonably extended range of values that could be expected is $5-100 \%$.

The dewpoint temperature is the temperature at which moist air saturates with respect to water at a given pressure. The dewpoint temperature can be measured precisely with a chilled-mirror hygrometer. The most widely used systems employ a small polished reflecting surface, cooled electrically by using a Peltier-effect device, and sense condensation with an optical detector (WMO, 2008). For Class 1 stations, high precision measurements of the dew point with such a device are recommended. Conversions into any other moisture measure can be performed with air temperature and pressure.

Technical issues:

Most of the $R H$ sensors must be shielded to protect the probes from the interference with radiation, wind and any other external force that could affect water vapour interaction with the detector. In particular, sensors that are based on electrical capacitive hygrometers must be protected 
from rain, solar radiation, wind, and dust or frost deposition. This is similar to shielding for measurements of air temperature so that sensors for air temperature and relative humidity can be placed in the same screen. A good natural/ forced air circulation must be guaranteed by the enclosure to avoid the formation of microclimates in the measuring volume. For the housing, only appropriate materials, nonadsorbing or non-desorbing liquid water and water vapour must be used.

The selected instrument has to fulfil criteria requested for WMO working standards for accuracy and precision, which has to be high enough to allow a measurement uncertainty in the order of magnitude of $2 \%$ in the range of 5 to $100 \%$ relative humidity (WMO, 2014) and a response time in the range of 20 to $40 \mathrm{~s}$ or lower (see appendix A6 for definitions of accuracy, precision and response time). Long-term stability and robustness under all weather conditions have to be guaranteed in order to provide stability over a period of at least two years.

Variability in time and space:

Like most other micrometeorological variables, $R H$ can vary in time and space within the footprint of the micrometeorological tower. This is mainly true if relevant inhomogeneity of the surface occurs on small spatial scales, i.e. on the order $10^{0} \mathrm{~m}$ to $10^{2} \mathrm{~m}$, or if the vertical variation inside the canopy is of interest (e.g. forests). The time evolution of this variable is primarily driven by radiation, wind and moisture content at the surface and the half-hourly time scale used to estimate other micrometeorological variables is adequate in this case. Turbulent fluctuations are not relevant for this variable. This means that the step response time (see A6) for specified accuracy and precision levels must of the order of 30s. Measurements of a vertical water vapour profile should be performed in conjunction with the $\mathrm{CO}_{2}$-profile to be able to consider storage fluxes of water vapour below the $\mathrm{EC}$ measurements.

Measurement method and instrument recommendations:

Several methods are accepted by the WMO for the measurement of $R H$ (WMO, 2014) by:

1. electrical capacitive hygrometry,

2. dew point temperature estimation by condensation on chilled mirrors,

3. the psychrometric method,

4. absorption of electromagnetic radiation (infra-red or ultraviolet).

Most common and easy to use instruments based on electrical capacitive hygrometers are slightly less accurate than chilled mirrors but provide a reasonable level of accuracy in the measurement range with continuous time series and have a shorter response time which makes them suitable for ICOS requirements. The accuracy is in general between 2 and $3 \%$.
The method based on chilled (or frozen) mirrors for the estimation of the dew point temperature allows the best accuracy in measurements of $R H$, with the only drawbacks of being an indirect measurement method and the slow response time, generally not compliant with the required threshold of $20 \mathrm{~s}$. Moreover, the instruments do not require particular shielding, one of the most relevant feature to be considered because the screen can introduce a significant and difficult to estimate the source of errors. The dew point mirror has to be used together with a small pump that provides the gas flow over the chilled surface. The inlet of the airstream should be close to the EC and accompanying measurements.

The electrical capacitive hygrometers are the default kind of instrument to measure $R H$ at ICOS stations and, if possible, in combination with higher accuracy measurements through chilled mirror hygrometers for cross-calibration of the sensors and methods. The chilled-mirrors could be used as a temporary reference for field calibration and check of the default capacitive hygrometers, whenever its long-term use is hard to achieve. However, their installation is not mandatory at ICOS ecosystem stations.

\section{Air pressure}

The atmospheric pressure on a given surface is the force per unit area exerted by virtue of the weight of the atmosphere above. The pressure is thus equal to the weight of a vertical column of air above a horizontal projection of the surface, extending to the outer limit of the atmosphere (WMO, 2014).

The fundamental physical unit for atmospheric pressure $p$ is Pascal (Pa) and corresponds to a force of one Newton orthogonally exerted above one square meter surface: $1 \mathrm{~Pa}$ $=1 \mathrm{~N} \mathrm{~m}^{-2}$.

The range of physically measurable values depends on the synoptic variation of atmospheric pressure as well as on altitudinal variations because the air pressure decreases exponentially with altitude above sea level. An extended range of ICOS ecosystem measurement stations is $650-$ $1080 \mathrm{hPa}$.

The lowest limit of $650 \mathrm{hPa}$ is significantly lower than normal atmospheric pressure values at most of the ICOS ecosystem stations and can be increased to achieve better accuracy within the measured amplitude range. The lowest reference value $\left(p_{0}\right)$ can be considered $850 \mathrm{hPa}$ at sea level and then the height adjusted value decreases according to the barometric pressure law (constant temperature and humidity):

$$
p(h)=p_{0} \exp \left(-\frac{g M h}{R T_{0}}\right),
$$

$h$ : height above sea level, $g$ : acceleration due to gravity, $M$ : molar mass of dry air, $R$ : universal gas constant, $T_{0}$ : sea level standard temperature. 
Technical requirements:

The level of accuracy needed for pressure measurements to satisfy the requirements of various meteorological applications is adopted from the WMO (2008) protocol but can be relaxed especially with respect to measurement range according to typical values for the respective station considering site elevation and long-term minima and maxima. Barometers with recent designs make use of transducers which transform the sensor response into pressure-related quantities. The measurement method for the purpose of continuous sampling has to be an electronic barometer fulfilling requirements according to WMO standards or as close as possible to this. For accuracy and precision, WMO states that the ideal accuracy for air pressure sensors is $0.1 \mathrm{hPa}$ (WMO, 2014). For ICOS ecosystem stations, this accuracy requirement can be relaxed to a measurement uncertainty threshold of $0.3-0.5 \mathrm{hPa}$ to make the choice and installation of the sensor more feasible. Precision should be $\pm 0.5 \mathrm{hPa}$ and the response time in the range of 20 to $40 \mathrm{~s}$. The long-term stability and robustness to all weather conditions has to be guaranteed in order to provide stability over a period of at least two years.

Variability in time and space:

Except for extreme meteorological events such as tornadoes or hurricanes, the air pressure variations are slow compared to high-frequency time scales of EC measurements and normally belong to timescale ranges between 1 minute and few hours.

The atmospheric pressure has to be measured at the measurement station because its value is needed to characterize meteorological conditions and to correct other measurements. However, the atmospheric pressure is not changing significantly on horizontal scales of the order of $10^{2} \mathrm{~m}$ and vertical of $10 \mathrm{~m}$. This means that the barometer doesn't strictly need to be placed at small distances from the EC system as other measurement devices do. An electronic barometer measures the atmospheric pressure of the surrounding space or any space that is connected to it via a tube. This tube has to be connected to a static pressure head to avoid pressure fluctuations caused by wind gusts. For the wind-induced dynamic pressure fluctuations, some specific screen or device is normally available by the producers. To avoid mechanical vibrations a positioning at the measurement station has to be chosen that should reduce as much as possible any interference with other devices. Screening of direct solar radiation and rain is advisable.

Recommended instruments:

Instruments should be selected from the category of electronic barometers.

Air temperature and relative humidity sensors have to be placed at the same location as this is needed for the calculation of other humidity entities as mentioned above. The atmospheric pressure can be measured at other heights and be re-calculated for the measurement height using elevation difference, air temperature and humidity of the air column between the pressure sensor and the humidity sensor. All sensors for air temperature, moisture and pressure are run in continuous mode with a sampling and data logging rate of minimum $0.033 \mathrm{~Hz}$, corresponding to 2 samples per minute, to detect time evolution of the variables. Raw data with instrument units and physical units collected must be stored and transmitted to the ETC daily. All postprocessing is centrally performed by the ETC. In addition information such as calibration sheets, positions of the sensors, date of modifications or malfunctioning must be provided through metadata.

\section{Back-up meteorological data}

Relevant meteorological variables that drive ecosystem processes and are needed for EC quality insurance have to be provided additionally by an autonomous meteorological station. This meteorological station has to have an independent power supply and shall be able to store all data at least internally. However, regular automatic data transfer to the home institution should be preferred. Also, sampling and storage procedures may be relaxed compared to the procedures described above. The station shall be equipped with sensors for the determination of the incoming shortwave radiation, air temperature, air humidity and precipitation similar to the above-described standards with measurement heights around $2.5 \mathrm{~m}$ from the soil and avoiding shading or thermal influence from surrounding infrastructures, ecosystem or vegetation elements (WMO, 2014). The station has to be in a distance less than $1 \mathrm{~km}$ from the main station to ensure meteorological variables to be representative of the ecosystem under investigation. For tall vegetation such as forests, a clearing close to the main station may be difficult to find within a distance of $1 \mathrm{~km}$. In such case the backup-instrumentation may be installed on the tower itself, supported by an independent power supply and an independent data acquisition.

\section{Logbook and meta-data}

A (possibly online) logbook has to be kept. The logbook has to include IRGA and sonic factory calibration coefficients, all maintenance operations with their date and weather conditions, all calibration operations with their date, temperature, observed zero and span offsets of the analyser before calibration and all intermediate zero readings. All this information, as well as general information about the set-up, have to be provided to the ETC via the meta-data system.

\section{SPATIAL REPRESENTATIVENESS OF THE MEASUREMENTS}

The spatial representativeness and location bias of fluxtower measurements need to be determined, meaning the area from which the observed fluxes originate, should be 
estimated and described. A flux footprint is an essential tool for selecting the measurement station, for the planning of EC experiments and interpretation of resulting data. The flux footprint describes the 'field of view' or 'source area' of the EC system, providing the relative contribution of each surface element to the measured vertical flux. It depends on measurement height, surface roughness and atmospheric stability. The footprint for EC flux measurements typically covers an area of a few hectares to square kilometres. Variations in footprint size and wind direction lead to a more or less regular or irregular sampling of the areas surrounding the tower. The degree of heterogeneity within the footprint of the tower will be evaluated by an intensive sampling of the soil and vegetation as described in other papers of this issue.

Footprints cannot be measured directly but are derived based on atmospheric dispersion models or analytical solutions of the diffusion equation. For both, footprint models and measurements of atmosphere-surface exchange, ideally, the area in the flux footprint should be horizontally homogeneous and of flat terrain with a well-developed turbulence field. Hence the species coverage, canopy height and thermal properties of the surface of interest should not vary significantly. In reality, these prerequisites are never fully met and typically the setup is optimized for certain wind directions or parts of the area of interest. Besides variations of the vegetation, height or structure, soil type and soil properties may vary, and groundwater depth may fluctuate locally. Such surface inhomogeneities directly influence the sources or sinks of the constituent measured and may complicate interpretation of the origin and representativeness of the observed flux.

Inhomogeneity modifies the footprint by modifying the turbulent flow field. In the case of a patchy terrain, knowledge of the source area and strength is required (Vesala et al., 2008). Also, edge effects occur commonly as a consequence of a limited fetch in many European forest sites (Eder et al., 2013; Kröniger et al., 2017). Model simulations suggest that abrupt roughness changes perturb both the flow and concentration fields in and above plant canopies, leading to significant horizontal and vertical advection of $\mathrm{CO}_{2}$ (Sogachev et al., 2008).

The influence of surface heterogeneity on the flux data quality can be evaluated using footprint modelling (Chasmer et al., 2011; Foken and Leclerc, 2004; Göckede et al., 2004). The area in the direct surrounding of the tower (which is often not representative due to canopy cutting, flow distortion by tower and fences, etc.) contributes more to the measured flux if surface roughness is high, boundarylayer conditions are very unstable or if the measurement height is small (Kljun et al., 2002). Moreover footprint models are extremely sensitive to surface roughness and refined estimates of the roughness length and displacement height parameters at each site, normally referred to in literature as $z_{o}$ and $d$ (Foken, 2008; Leclerc and Foken,
2014). Turbulence profiles or LIDAR data, can lead to an improved agreement between modeled and experimentally estimated footprints (Arriga et al., 2017; Heidbach et al., 2017; Kljun et al., 2015), resulting in a better interpretation of the ecosystem fluxes for each EC station.

Several theoretical approaches have been proposed for the determination of the footprint. These models can be classified into four categories: Analytical models, Lagrangian stochastic models, large-eddy simulations and ensemble-averaged closure models, as summarized by Schmid (2002), Vesala et al. (2008) and Leclerc and Foken (2014). Some of these models have been used for deriving simplified parameterizations that require minimal computational efforts. Because of their theoretical simplicity and their ease of use, these parameterizations and analytical models are especially suitable for practical applications such as EC measurement site design (Horst and Weil, 1992, 1994; Hsieh et al., 2000; Kljun et al., 2004, 2015; Kormann and Meixner, 2001; Schmid, 1994). Additionally, practical applications have been developed that simplify these original algorithms in user-friendly online tools (Vesala et al., 2008). Examples are the parametrization by Kljun et al. $(2004,2015)$ that can be found at http://footprint.kljun. net or the 'Footprint calculator', a simplified version of the SCADIS closure model (Sogachev and Sedletski, 2006). Within the ICOS-network, the parameterization by Kljun et al. (2015) is applied, as this footprint model uses an optimal combination of different existing methods.

It should be noted that the above models are limited to flat and homogeneous surfaces. Analytical approaches are further constrained to surface layer conditions. Simple and fast footprint models only provide approximate results for complex terrain and tall vegetation, for which more sophisticated models such as Sogachev et al. (2004) and Steinfeld et al. (2008) are preferable but still computationally too expensive to be applied on continuous long-term data sets.

Often, the one-dimensional crosswind-integrated footprint (IF) is of main interest to EC measurements. It may be further expressed as cumulative footprint (CIF), i.e. effective fetch. CIF provides a criterion for estimating the minimum fetch required for a representative flux measurement, meaning that a certain percentage of the observed flux must originate from the surface of interest. Here we suggest a CIF of minimum $80 \%$ for an acceptable measurement, where the footprint function is integrated from the footprint peak location into all directions along constant levels of footprint values until the contribution of interest (i.e. $80 \%$ ) is obtained (taking into account possible directional variations). CIF should be calculated for different meteorological conditions representing day-night differences and seasonal variation. As turbulence measurements are seldom available for the site design phase, typical combinations of input variables required for the model should be assumed. Another possibility is to use actual turbulence statistics if these are available for the site (from a close-by 
meteorological station). In both approaches, the effect of measurement height and surface rougness on footprint size and extent can be tested.

Both these exercises may be conducted by using the simple analytical models or simplified parameterisations listed above. The required input data depend on the model. For example, the following input data are needed when calculating CIF with the model presented by Kormann and Meixner (2001): measurement height, roughness length, wind speed or friction velocity, and Obukhov length. The model of Kljun et al. (2004) and the two-dimensional models of Hsieh et al. (2000), Detto et al. (2006), and Kljun et al. (2015) are applicable in a wider range of atmospheric conditions. For a full application they will need estimates of the planetary boundary layer height as input (see suggestions in Kljun et al. (2015) for estimation of the planetary boundary layer), as well as the vertical wind speed variance or the lateral wind speed variance, respectively.

\section{RESULTS AND DISCUSSION}

The increasing need for earth observation strategies including terrestrial carbon observations requires networks to determine spatial distributions and temporal evolutions of terrestrial fluxes and stocks of carbon and related entities (Raupach et al., 2005). Eddy covariance measurements can be made on a quasi-continuous basis to assess ecosystem exchange of trace gas and water fluxes between ecosystems and the atmosphere. The technique allows the evaluation of ecosystem fluxes across a spectrum of timescales, ranging from hours to years (Baldocchi, 2003; Baldocchi et al., 2001) and enables thereby the detection of inter- and intraannual variations of the terrestrial net ecosystem exchange in response to environmental variables. In addition, EC data are highly valuable for the improvement and evaluation of land surface models and their parameterizations especially with respect to the biogeochemical processes (Baldocchi, 2014; Haughton et al., 2018; Post et al., 2017; Tramontana et al., 2016). The EC technique is a widely accepted methodology in the scientific community around the globe and has thus evolved as the method of choice in the last decades in several regional and global networks such as Euroflux, AmeriFlux, NEON, SAEON, AsiaFlux, OzFlux and FLUXNET (Aubinet et al., 2000; Baldocchi et al., 2001; Novick et al., 2017; Yamamoto et al., 2005; Keller et al., 2008; van Jaarsveld et al., 2007). However, only when applying the instrumentation properly and performing a well-established data post-processing, fluxes become comparable across different regions, ecosystems and sites. Open questions with respect to GHG exchange, e.g. the inter-annual variability or long-term trends can only be detected with stable and standardised methods. In parallel to the development of the instrumentation, especially so for trace gases, tools to describe data quality (Foken and Wichura, 1996; Vickers and Mahrt, 1997), flux uncertainty
(Billesbach, 2011; Mauder et al., 2013), footprints (Kljun et al., 2015; Leclerc and Foken, 2014; Sogachev et al., 2004; Vesala et al., 2008) and their combination (Göckede et al., 2008) have been further addressed and are applied within the ecosystem component of ICOS.

Although the EC technique has matured substantially over the last decades (Aubinet et al., 2012, Baldocchi et al., 2017) and can now be applied successfully by non-specialists, it has by no means reached a true 'plug-and-play' level (Eugster and Merbold, 2015; Baldocchi, 2014). Several issues and unsolved questions with regard to the technique itself remain active research topics today and have largely prevented the formulation and adoption of universally accepted standards in instrumentation, data analysis, and uncertainty estimation. The latter point, in particular, applies to both the EC-system as a whole as well as to its component instruments. Several studies exploring sources of systematic bias (and proposing correction schemes), or random and systematic uncertainty for various aspects or components of EC systems have been published (e.g. Mauder et al., 2013; Richardson et al., 2012). The most likely reason for thwarting significant progress in systematic and random uncertainty estimation is the absence of an absolute reference to gauge EC systems performance. The same difficulty applies to the turbulence measurement part of the system (usually by ultrasonic anemometer) because, (1) the magnitude and spectral range of common atmospheric boundary-layer turbulence cannot be reproduced in a wind-tunnel, and (2) laboratory calibrations against absolute velocity standards do not represent the conditions which the sensors are exposed to in the field. As a result, the transferability of such calibrations and instrument quality assessments (often only available by the instrument manufacturers) to the field remains limited. While field calibrations only address inter-comparisons of different sensors or systems with unknown absolute errors, they often shed more light on the behavior of random instrument uncertainty as a function of environmental conditions (Billesbach, 2011; Dragoni et al., 2007; Finkelstein and Sims, 2001; Loescher et al., 2006; Richardson et al., 2006).

The challenge of large flux networks, established with the goal of detecting perturbations of the global carbon cycle as well as driving forces modulating GHG fluxes, is to ensure comparability of flux data over time and space (Baldocchi et al., 2016, 2017). Therefore within ICOS, it was decided to standardise the instrumentation at all sites across the network for the key variables such as net exchange of $\mathrm{CO}_{2}, \mathrm{H}_{2} \mathrm{O}$ and energy. Driving and accompanying variables are also measured, acquired and transferred in a standardised way, even though more flexibility is given with respect to the selection of instruments. For the EC instrumentation it was decided to use the same instruments -namely the GILL HS and the LI-7200 - at all stations 
during the initial phase of ICOS. However, ICOS will consider new technologies during its runtime in case of an improved performance compared to the initial instrument set. In addition to the stations that will deliver their data in a standardised manner, either as Class 1 or Class 2 stations, additional data are provided to the ICOS network from ecosystem sites with lower standards but valuable ecological contributions. Over time, these Associated stations may also standardise their measurements according to the protocols for more reliable cross-site synthesis. But these stations also offer the possibility to develop and test new techniques. Especially with respect to the EC instrumentation and data acquisition new developments are needed to ensure best practice on a long-term basis. An extension of the network should not only consider new sites and ecosystems but also spatial replications of EC measurements at the ecosystem scale to increase the statistical power of flux measurements and thus the ability to provide statistically robust flux estimates for larger areas (Hill et al., 2017).

The aim of flux networks is to compare ecosystems in different areas around the globe. However, we also have to ensure that the investigated ecosystems are representative beyond the flux footprint and capture natural variability of climatological and biological conditions to enable reasonable upscaling for continental carbon balance determination (Chu et al., 2017). Bearing this in mind, we have to ensure that the results achieved across time, biomes and ecosystems stay comparable by regular calibration, standardisation and traceability of methods.

\section{CONCLUSIONS}

1. Carbon cycle perturbations need to be determined in a standardised way with high-precision and long-term observations of $\mathrm{C}, \mathrm{N}$ and other GHGs based on in-situ measurements.

2. The ICOS ecosystem station network provides GHG fluxes and complementing measurements for terrestrial and freshwater ecosystems to identify and understand their exchange dynamics as well as their role in $\mathrm{C}$ cycling with regard to climate change.

3. Reliability and comparability of acquired data over time and space are assured by the high level of standardisation of the hardware, software and field operation across the ICOS network.

4. The determination of trace gas and energy exchange between the biosphere and the atmosphere with the EC technique - the core measurements at ICOS ecosystem stations - are performed with the same sets of instrumentation to avoid methodological differences.

5. The extension of the network has to consider new developments while ensuring comparability over time and space.

\section{ACKNOWLEDGMENTS}

This manuscript is based on protocols developed by three working groups on sonic anemometry, gas analyser and the set-up of eddy covariance sites. We acknowledge all active members of the ICOS ecosystem working groups and all other people who contributed to the development of the ICOS ecosystem domain and the measurement protocols.

CR is financed by the Helmholtz Centre for Environmental Research GmbH - UFZ, Leipzig, Germany and received funding by the BMBF. AG would like to thank the German Federal Ministry of Education and Research for funding (grant 01LN1313A). LM and LH acknowledge funds received under the Swiss National Science Foundation-funded project ICOS-CH (grant agreement: 20FI21_128992) and of ETH Zurich (0-23184-15). NA acknowledges ICOS-Belgium and Fonds Wetenschappelijk Onderzoek (FWO) for financial and logistic support. The National Ecological Observatory Network is a project sponsored by the National Science Foundation and managed under cooperative agreement by Battelle Ecology, Inc. This material is based upon work supported by the National Science Foundation (grant DBI-0752017). Any opinions, findings, and conclusions or recommendations expressed in this material are those of the author and do not necessarily reflect the views of the National Science Foundation. We would also like to thank Dr James Kathilankal and Mr Dave Johnson from LI-COR Biosciences for help checking the technical specifications of the EC hardware and software. In addition we acknowledge the valuable input of the two anonymous reviewers.

Conflict of interest: The Authors declare no conflict of interest.

\section{REFERENCES}

Arriga N., Rannik Ü., Aubinet M., Carrara A., Vesala T., and Papale D., 2017. Experimental validation of footprint models for eddy covariance $\mathrm{CO}_{2}$ flux measurements above grassland by means of natural and artificial tracers. Agric. For. Meteorol. 242: 75-84. doi:https://doi. org/10.1016/j.agrformet.2017.04.006.

Aubinet M., Berbigier P., Bernhofer C.H., Cescatti A., Feigenwinter C., Granier A., et al., 2005. Comparing $\mathrm{CO}_{2}$ storage and advection conditions at night at different CarboEuroflux sites. Boundary-Layer Meteorology 116: 63-94.

Aubinet M., Grelle A., Ibrom A., Rannik Ü., Moncrieff J., Foken T., et al., 2000. Estimates of the annual net carbon and water exchange of forests: the EUROFLUX methodology. Adv. Ecol. Res., 30. doi:10.1016/ s0065-2504(08)60018-5.

Aubinet M., Feigenwinter C., Heinesch B., Bernhofer C., Canepa E., Lindroth A., et al., 2010. Direct advection measurements do not help to solve the night-time $\mathrm{CO}_{2}$ 
closure problem: Evidence from three different forests. Agric. For. Meteorol. 150: 655-664. doi:http://dx.doi. org/10.1016/j.agrformet.2010.01.016.

Aubinet M., Joly L., Loustau D., De Ligne A., Chopin H., Cousin J., et al., 2016. Dimensioning IRGA gas sampling systems: laboratory and field experiments. Atmos. Meas. Tech., 9, 1361-1367. doi:10.5194/amt-9-361-2016.

Aubinet M., Vesala T., and Papale D., 2012. Eddy Covariance: A Practical Guide to Measurement and Data Analysis, Dordrecht.

Baldocchi D., 2014. Measuring fluxes of trace gases and energy between ecosystems and the atmosphere - the state and future of the eddy covariance method. Global Change Biol 20: 3600-3609. doi:10.1111/gcb.12649.

Baldocchi D., Chu H., and Reichstein M., 2017. Inter-annual variability of net and gross ecosystem carbon fluxes: A review. Agric. For. Meteorol., doi: https://doi. org/10.1016/j.agrformet.2017.05.015.

Baldocchi D., Falge E., Gu L.H., Olson R., Hollinger D., Running S., et al., 2001. FLUXNET: A new tool to study the temporal and spatial variability of ecosystemscale carbon dioxide, water vapor, and energy flux densities. Bull. Am. Meteorol. Soc., 82: 2415-2434.

Baldocchi D., Ryu Y., and Keenan T., 2016. Terrestrial Carbon Cycle Variability [version 1; referees: 2 approved]. F1000Research 2016, 5 (F1000 Faculty Rev): 2371 (doi: 10.12688/f1000research.8962.1).

Baldocchi D.D., 2003. Assessing the eddy covariance technique for evaluating carbon dioxide exchange rates of ecosystems: past, present and future. Global Change Biol., 9: 479-492.

Baldocchi D.D., Hicks B.B., and Meyers T.P., 1988. Measuring biosphere-atmosphere exchanges of biologically related gases with micrometeorological methods. Ecology, 69(5): 1331-1340.

Belcher S.E., Finnigan J.J., and Harman I.N., 2008. Flows through forest canopies in complex terrain. Ecol. Appl., 18: 1436-1453.

Billesbach D.P., 2011. Estimating uncertainties in individual eddy covariance flux measurements: A comparison of methods and a proposed new method. Agric. For. Meteorol., 151: 394-405, doi:10.1016/j.agrformet. 2010.12.001.

Bureau international des poids et mesures / Joint Committee for Guides in Metrology (BIPM/JCGM), 2008. Evaluation of Measurement Data-Guide to the expression of uncertainty in measurement (GUM). 100.

Bureau international des poids et mesures / Joint Committee for Guides in Metrology (BIPM/JCGM), 2008. International Vocabulary of Metrology - Basic and general concepts and associated terms(VIM). BIPM/JCGM.

Burba G., 2013. Eddy Covariance Method for Scientific, Industrial, Agricultural and Regulatory Applications: A Field Book on Measuring Ecosystem Gas Exchange and Areal Emission Rates, Lincoln, Nebraska.

Burba G., Anderson D., Furtaw M., Eckles R., McDermitt D., and Welles J., 2012a. Gas analyser. US Patent 8, 130,379. Date issued: March 6, 2012.

Burba G., Schmidt A., Scott R.L., Nakai T., Kathilankal J., Fratini G., et al., 2012b. Calculating $\mathrm{CO}_{2}$ and $\mathrm{H}_{2} \mathrm{O}$ eddy covariance fluxes from an enclosed gas analyzer using an instantaneous mixing ratio. Global Change Biol., 18: 385-399. doi:10.1111/j.1365-2486.2011. 2536.x.

Burba G.G., McDermitt D.K., Anderson D.J., Furtaw M.D. and Eckles R.D., 2010. Novel design of an enclosed $\mathrm{CO}_{2} / \mathrm{H}_{2} \mathrm{O}$ gas analyser for eddy covariance flux measurements. Tellus Ser. B-Chem. Phys. Meteorol., 62: 743-748. doi:10.1111/j.1600-0889.2010.00468.x.

Chasmer L., Kljun N., Hopkinson C., Brown S., Milne T., Giroux K., et al., 2011. Characterizing vegetation structural and topographic characteristics sampled by eddy covariance within two mature aspen stands using lidar and a flux footprint model: Scaling to MODIS. J. Geophys. Res.-Biogeosci. 116, doi: G0202610. 1029/2010jg001567.

Christen A., van Gorsel E., Andretta M., Calanca M., Rotach M., and Vogt R., 2000. Intercomparison of ultrasonic anemometers during the MAP-Riviera project. 9th Conf. Mountain Meteorol., August 7-11, Aspen, CO, USA.

Chu H., Baldocchi D.D., John R., Wolf S., and Reichstein M., 2017. Fluxes all of the time? A primer on the temporal representativeness of FLUXNET. J. Geophysical Res.: Biogeosciences 122: 2016JG003576, doi:10.1002/ 016JG003576.

Detto M., Montaldo N., Albertson J.D., Mancini M., and Katul G., 2006. Soil moisture and vegetation controls on evapotranspiration in a heterogeneous Mediterranean ecosystem on Sardinia, Italy. Water Resour. Res., 42, W08419, doi: 10.1029/2005WR004693.

Dragoni D., Schmid H.P., Grimmond C.S.B., and Loescher H.W., 2007. Uncertainty of annual net ecosystem productivity estimated using eddy covariance flux measurements. J. Geophys. Res., 112, D17102, doi:10.1029/ 2006JD008149.

Eder F., Serafimovich A., and Foken T., 2013. Coherent Structures at a Forest Edge: Properties, Coupling and Impact of Secondary Circulations. Boundary-Layer Meteorol., 148: 285-308, doi:10.1007/s10546-0139815-0.

Ediger K. and Riensche B.A., 2017. Systems and methods for measuring gas flux. US Patent 9,759,703. Date issued: September 12, 2012.

El-Madany T.S., Griessbaum F., Fratini G., Juang J.Y., Chang S.C., and Klemm O., 2013. Comparison of sonic anemometer performance under foggy conditions. Agric. For. Meteorol., 173: 63-73. doi:10.1016/j.agrformet. 2013.01.005.

Eugster W. and Merbold L., 2015. Eddy covariance for quantifying trace gas fluxes from soils. Soil, 1: 187-205. doi: 10.5194/soil-1-187-2015.

Feigenwinter C., Bernhofer C., Eichelmann U., Heinesch B., Hertel M., Janous D., et al., 2008. Comparison of horizontal and vertical advective $\mathrm{CO}_{2}$ fluxes at three forest sites. Agric. For. Meteorol., 148: 12-24. doi:http://dx. doi.org/10.1016/j.agrformet.2007.08.013.

Feigenwinter C., Molder M., Lindroth A., and Aubinet M., 2010. Spatiotemporal evolution of $\mathrm{CO}_{2}$ concentration, temperature, and wind field during stable nights at the Norunda forest site. Agric. For. Meteorol., 150: 692701. doi:10.1016/j.agrformet.2009.08.005. 
Finkelstein P.L. and Sims P.F., 2001. Sampling error in eddy correlation flux measurements. J. Geophys. Res., [Atmos.] 106: 3503-3509.

Finnigan J.J., Clement R., Malhi Y., Leuning R., and Cleugh H.A., 2003. A re-evaluation of long-term flux measurement techniques - Part I: Averaging and coordinate rotation. Bound. Lay. Met., 107: 1-48.

Foken T., 2008. Micrometeorology, Springer, Berlin.

Foken T., Aubinet M., and Leuning R., 2012. The eddy covariance method. In: Eddy Covariance: A Practical Guide to Measurement and Data Analysis (Eds M. Aubinet, T. Vesala and D. Papale). Springer, Dordrecht.

Foken T. and Leclerc M.Y., 2004. Methods and limitations in validation of footprint models. Agric. For. Meteorol., 127: 223-234.

Foken T., Leuning R., Oncley S.P., Mauder M., and Aubinet M., 2012. Corrections and data quality. In: Eddy Covariance: A Practical Guide to Measurement and Data Analysis (Eds M. Aubinet, T. Vesala and D. Papale). Springer, Dordrecht.

Foken T. and Wichura B., 1996. Tools for quality assessment of surface-based flux measurements. Agric. For. Meteorol., 78, doi:10.1016/0168-1923(95)02248-1.

Frank J.M., Massman W.J., Swiatek E., Zimmerman H.A., and Ewers B.E., 2016. All Sonic Anemometers Need to Correct for Transducer and Structural Shadowing in Their Velocity Measurements. J. Atmospheric Oceanic Technol., 33: 149-167. doi:10.1175/jtech-d-15-0171.1.

Franz D., et al., 2018. Towards long-term standardised carbon and greenhouse gas observations for monitoring Europe's terrestrial ecosystems. Int. Agrophys., 32, 439-455.

Fratini G., Ibrom A., Arriga N., Burba G., and Papale D., 2012. Relative humidity effects on water vapour fluxes measured with closed-path eddy-covariance systems with short sampling lines. Agric. For. Meteorol., 165: 53-63. doi:10.1016/j.agrformet.2012.05.018.

Fratini G., McDermitt D.K., and Papale D., 2014. Eddycovariance flux errors due to biases in gas concentration measurements: origins, quantification and correction. Biogeosciences, 11:1037-1051.doi:10.5194/bg-11-10372014.

Furtaw M., EcklesR.,, Burba G., McDermitt D., and Welles J., 2012a. Gas analyser. US Patent US 8,300,218. Date issued: October 30, 2012.

Furtaw M., Eckles R., Burba G., McDermitt D., and Welles J., 2012b. Gas analyser. US Patent US 8,154,714. Date issued: April 10, 2012.

Gielen B., Op de Beeck M., Loustau D., Ceulemans R., Jordan A., and Papale D., 2017. Integrated carbon observation system (ICOS): An Infrastructure to Monitor the European Greenhouse Gas Balance. In: Terrestrial ecosystem research infrastructures: challenges and opportunities (Ed. A. Chabbi). CRC Press, Boca Raton, FL, USA.

GILL, 2017. HS-50 and HS-100 User manual, 3 Axis Horizontally Symmetric Ultrasonic Anemometers. Lymington, Hampshire, UK.

Göckede M., Foken T., Aubinet M., Aurela M., Banza J., Bernhofer C., et al., 2008. Quality control of
CarboEurope flux data - Part I: Coupling footprint analyses with flux data quality assessment to evaluate sites in forest ecosystems. Biogeosciences, 5: 433-450.

Göckede M., Rebmann C., and Foken T., 2004. A combination of quality assessment tools for eddy covariance measurements with footprint modelling for the characterisation of complex sites. Agric. For. Meteorol., 127: 175-188. doi:http://dx.doi.org/10.1016/j.agrformet.2004.07.012.

Griessbaum F. and Schmidt A., 2009. Advanced tilt correction from flow distortion effects on turbulent $\mathrm{CO}_{2}$ fluxes in complex environments using large eddy simulation. Q. J. R. Meteorol. Soc., 135: 1603-1613. doi:10.1002/qj.472.

Hargrove W.W. and Hoffman F.M., 1999. Using multivariate clustering to characterize ccoregion borders. Computing Sci. Eng., 1: 18-25, doi:doi:10.1109/5992.774837.

Hargrove W.W. and Hoffman F.M., 2004. Potential of multivariate quantitative methods for delineation and visualization of ecoregions. Environ. Manag., 34: S39-S60, doi:10.1007/s00267-003-1084-0.

Haslwanter A., Hammerle A., and WohlfahrtG., 2009. Openpath vs. closed-path eddy covariance measurements of the net ecosystem carbon dioxide and water vapour exchange: A long-term perspective. Agric. For. Meteorol. 149: 291-302.

Haughton N., Abramowitz G., De Kauwe M.G., and Pitman A.J., 2018. Does predictability of fluxes vary between FLUXNET sites? Biogeosciences Discuss. 2018: 1-32. doi:10.5194/bg-2018-179.

Heidbach K., Schmid H.P., and Mauder M., 2017. Experimental evaluation of flux footprint models. Agric. For. Meteorol. 246: 142-153. doi: https://doi.org/10.1016/j. agrformet.2017.06.008.

Hill T., Chocholek M., and Clement R., 2017. The case for increasing the statistical power of eddy covariance ecosystem studies: why, where and how? Global Change Biol 23: 2154-2165. doi:10.1111/gcb.13547.

Hinckley E.-L.S., Anderson S.P., Baron J.S., Blanken P.D., BonanG.B., Bowman W.D., et al., 2016. Optimizing available network resources to address questions in environmental biogeochemistry. Bioscience, 66: 317326, doi:10.1093/biosci/biw005.

Horst T.W. and Lenschow D.H., 2009. Attenuation of scalar fluxes measured with spatially-displaced sensors. Boundary-Layer Meteorol., 130: 275-300, doi:10.1007/ s10546-008-9348-0.

Horst T.W. and Weil J.C., 1992. Footprint estimation for scalar flux measurements in the atmospheric surface layer. Bound. Lay. Met., 59: 279-296.

Horst T.W. and Weil J.C., 1994. How far is far enough - the fetch requirements for micrometeorological measurement of surface fluxes. J. Atmospheric Oceanic Technol., 11: 1018-1025. doi:10.1175/1520-0426(1994)011<1018:hfi fet $>2.0 . \mathrm{co} ; 2$.

Hsieh C.-I., Katul G.G., and Chi T.-W., 2000. An approximate analytical model for footprint estimation of scaler fluxes in thermally stratified atmospheric flows. Adv. Water Res., 23: 765-772.

Huq S., De Roo F., Foken T., and Mauder M., 2017. Evaluation of Probe-induced flow distortion of campbell csat3 sonic anemometers by numerical simulation. BoundaryLayer Meteorology 165: 9-28. doi:10.1007/s10546017-0264-z. 
Ibrom A., Dellwik E., Flyvbjerg H., Jensen N.O., and Pilegaard K., 2007a. Strong low-pass filtering effects on water vapour flux measurements with closed-path eddy correlation systems. Agric. For. Meteorol., 147: 140-156.

Ibrom A., Dellwik E., Larsen S.E., and Pilegaard K., 2007b. On the use of the Webb-Pearman-Leuning theory for closed-path eddy correlation measurements. Tellus Ser. B-Chem. Phys. Meteorol., 59B: 937-946. DOI: 10.1111/ j.1600-0889.2007.00311.x.

International Organization for Standardization (ISO), 2007. Meteorology - Air temperature measurements - Test methods for comparing the performance of thermometer shields/screens and defining important characteristics. https://www.iso.org/obp/ui/\#iso:std:o:17714: ed-1:v1:en

International Organization for Standardization (ISO), 2009. Quantities and Units - Part 9: Physical Chemistry and Molecular Physics, ISO 80000-9:2009, https://www.iso. org/standard/31894.html

Kaminski T. and Rayner P.J., 2017. Reviews and syntheses: guiding the evolution of the observing system for the carbon cycle through quantitative network design. Biogeosciences 14: 4755-4766, doi:10.5194/bg-144755-2017.

Keller M., Schimel D.S., Hargrove W., and Hoffman F.M., 2008. A continental strategy for the National Ecological Observatory Network. Front. Ecol. Environ., 6: 282284.doi:10.1890/1540-9295(2008)6[282:ACSFTN]2.0. $\mathrm{CO} ; 2$.

Kim J., Guo Q., Baldocchi D.D., Leclerc M., Xu L., and Schmid H.P., 2006. Upscaling fluxes from tower to landscape: Overlaying flux footprints on high-resolution (IKONOS) images of vegetation cover. Agric. For. Meteorol., 136: 132-146.

Kljun N., Calanca P., Rotach M.W., and Schmid H.P., 2004. A simple parameterisation for flux footprint predictions. Boundary-Layer Meteorol., 112: 503-523.

Kljun N., Calanca P., Rotach M.W., and Schmid H.P., 2015. A simple two-dimensional parameterisation for Flux Footprint Prediction (FFP). Geosci. Model Dev., 8: 3695-3713. doi:10.5194/gmd-8-3695-2015.

Kljun N., Rotach M.W., and Schmid H.P., 2002. A three-dimensional backward Lagrangian footprint model for a wide range of boundary-layer stratifications. Bound. Lay. Met., 103: 205-226.

Kormann R. and Meixner F.X., 2001. An analytical footprint model for non-neutral stratification. Bound. Lay. Met., 99: 207-224.

Kowalski A.S. and Serrano-Ortiz P., 2007. On the relationship between the eddy covariance, the turbulent flux, and surface exchange for a trace gas such as $\mathrm{CO}_{2}$. BoundaryLayer Meteorol., 124: 129-141.

Kristensen L., Mann J., Oncley S.P., and Wyngaard J.C., 1997. How close is close enough when measuring scalar fluxes with displaced sensors? J. Atmospheric Oceanic Technol., 14: 814-821.

Kröniger K., Banerjee T., De Roo F., and Mauder M., 2017. Flow adjustment inside homogeneous canopies after a leading edge - An analytical approach backed by LES. Agric. For. Meteorol. doi: https://doi.org/10.1016/j. agrformet.2017.09.019.
Lacombe M., Bousri D., Leroy M., and Mezred M., 2011. WMO Field intercomparison of Themometer Screens / Shields and Hygrometers in hot desert conditions. In: Instruments and Observing Methods (Ed. W.M.O.) WMO, Geneva, Switzerland.

Lasslop G., Reichstein M., Kattge J., and Papale D., 2008. Influences of observation errors in eddy flux data on inverse model parameter estimation. Biogeosciences, 5: 1311-1324.

Leclerc M.Y. and Foken T., 2014. Classification of Footprint Models. Springer, Berlin Heidelberg.

Lee X., Massman W., and Law B., 2004. Handbook of Micrometeorology: A Guide for Surface Flux Measurement and Analysis. Kluwer Academic Publisher, Dordrecht.

Le Quéré C., Andrew R.M., Canadell J.G., Sitch S., Korsbakken J.I., Peters G.P., et al., 2016. Global carbon budget 2016. Earth Syst. Sci. Data 8: 605-649. doi:10.5194/essd-8-605-2016.

Leuning R. and Judd M.J., 1996. The relative merits of openand closed-path analysers for measurement of eddy fluxes. Global Change Biol., 2 (3): 241-253.

LI-COR, 2014. LI-7200 Enclosed $\mathrm{CO}_{2} / \mathrm{H}_{2} \mathrm{O}$ Gas Analyzer Instruction Manual. In: I. LI-COR (editor) Lincoln, Nebraska 68504 USA.

Loescher H.W., Law B.E, Mahrt L., Hollinger D.Y., Campbell J., and Wofsy S.C., 2006. Uncertainties in, and interpretation of, carbon flux estimates using the eddy covariance technique. J. Geophys. Res., [Atmos.] 111.

Mammarella I., Launiainen S., Grönholm T., Keronen P., Pumpanen J., Rannik Ü., et al., 2009. Relative humidity effect on the high-frequency attenuation of water vapor flux measured by a closed-path eddy covariance system. J. Atmospheric Oceanic Technol., 26: 18561866. doi:10.1175/2009jtecha1179.1.

Mauder M., Cuntz M., Drüe C., Graf A., Rebmann C., and Schmid H.P., 2013. A strategy for quality and uncertainty assessment of long-term eddy-covariance measurements. Agric. For. Meteorol., 169. doi:10.1016/j. agrformet.2012.09.006.

Mauder M., Oncley S.P., Vogt R., Weidinger T., Ribeiro L., Bernhofer C., et al., 2007. The energy balance experiment EBEX-2000. Part II: Intercomparison of eddy-covariance sensors and post-field data processing methods. Boundary-Layer Meteorol., 123: 29-54.

Mauder M. and Zeeman M.J., 2018. Field intercomparison of prevailing sonic anemometers. Atmos. Meas. Tech., 11: 249-263. doi:10.5194/amt-11-249-2018.

Metzger S., Burba G., Burns S.P., Blanken P.D., Li J., Luo H., et al., 2016. Optimization of an enclosed gas analyzer sampling system for measuring eddy covariance fluxes of $\mathrm{H}_{2} \mathrm{O}$ and $\mathrm{CO}_{2}$. Atmos. Meas. Tech., 9: 1341-1359. doi:10.5194/amt-9-1341-2016.

Moore C.J., 1986. Frequency response corrections for eddy correlation systems. Bound. Lay. Met., 37: 17-35.

Munger J.W., Loescher H.W., and Luo H., 2012. Measurement, Tower, and Site Design Considerations. In: Eddy Covariance - A Practical Guide to Measurement and Data Analysis (Eds M. Aubinet, T. Vesala and D. Papale). Springer, Dordrecht.

Nakai T., Iwata H., and Harazono Y., 2011. Importance of mix- 
ing ratio for a long-term $\mathrm{CO}_{2}$ flux measurement with a closed-path system. Tellus B: Chemical and Physical Meteorology, 63: 302-308. doi:10.1111/j.1600-0889. 2011.00538.x.

Nicolini G., Aubinet M., Feigenwinter C., Heinesch B., Lindroth A., Mamadou O., et al., 2018. Impact of $\mathrm{CO}_{2}$ storage flux sampling uncertainty on net ecosystem exchange measured by eddy covariance. Agr. Forest Meteorol., 248, 228-239.

Novick K.A., Biederman J.A., Desai A.R., Litvak M.E., Moore D.J.P., Scott R.L., et al., 2017. The AmeriFlux network: A coalition of the willing. Agric. For. Meteorol. doi: https://doi.org/10.1016/j.agrformet.2017.10.009.

Papale D., Black T.A., Carvalhais N., Cescatti A., Chen J., Jung M., et al., 2015. Effect of spatial sampling from European flux towers for estimating carbon and water fluxes with artificial neural networks. J. Geophysical Res.: Biogeosci., 120: 1941-1957. doi:10.1002/ 2015JG002997.

Post H., Vrugt J.A., Fox A., Vereecken H., and Hendricks Franssen H.-J., 2017. Estimation of community land model parameters for an improved assessment of net carbon fluxes at European sites. J. Geophysical Res.: Biogeosci., 122: 661-689. doi:10.1002/2015JG003297.

Rannik Ü., Kolari P., Vesala T., and HariP., 2006. Uncertainties in measurement and modelling of net ecosystem exchange of a forest. Agric. For. Meteorol., 138: 244-257.

Rannik Ü., Sogachev A., Foken T., Göckede M., Kljun N., Leclerc M., et al., 2012. Footprint Analysis. In: Eddy Covariance: A Practical Guide to Measurement and Data Analysis (Eds M. Aubinet, T. Vesala and D. Papale). Springer, Dordrecht.

Raupach M.R., Rayner P.J., Barrett D.J., DeFries R.S., Heimann M., Ojima D.S., et al., 2005. Model-data synthesis in terrestrial carbon observation: methods, data requirements and data uncertainty specifications. Global Change Biol., 11: 378-397.

Rebmann C., Kolle O., Heinesch B., Queck R., Ibrom A., and Aubinet M., 2012. Data Acquisition and Flux Calculations. In: Eddy Covariance: A Practical Guide to Measurement and Data Analysis (Eds M. Aubinet, T. Vesala and D. Papale). Springer, Dordrecht.

Richardson A.D., Aubinet M., Barr A.G., Hollinger D.Y., Ibrom A., Lasslop G., et al., 2012. Uncertainty Quantification. In: Eddy Covariance: A Practical Guide to Measurement and Data Analysis (Eds M. Aubinet, T. Vesala and D. Papale). Springer, Dordrecht.

Richardson A.D., Hollinger D.Y., Burba G.G., Davis K.J., Flanagan L.B., Katul G.G., et al., 2006. A multi-site analysis of random error in tower-based measurements of carbon and energy fluxes. Agric. For. Meteorol., 136: $1-18$.

Schmid H.P., 1994. Source areas for scalars and scalar fluxes. Bound. Lay. Met., 67: 293-318.

Schmid H.P., 1997. Experimental design for flux measurements: matching the scale of the observations to the scale of the flux. Agric. For. Meteorol., 87: 179-200.
Schmid H.P., 2002. Footprint modeling for vegetation atmosphere exchange studies: a review and perspective. Agric. For. Meteorol., 113: 159-183.

Schmid H.P. and Lloyd C.R., 1999. Spatial representativeness and the location bias of flux footprints over inhomogeneous areas. Agric. For. Meteorol., 93: 195-209.

Schotanus P., Nieuwstadt F.T.M., and De Bruin H.A.R., 1983. Temperature measurements with a sonic anemometer and its application to heat and moisture fluxes. Bound. Lay. Met., 26: 81-93.

Serafimovich A., Thomas C., and Foken T., 2011. Vertical and horizontal transport of energy and matter by coherent motions in a tall spruce canopy. Boundary-Layer Meteorology, 140: 429-451. doi:10.1007/s10546-0119619-z.

Sogachev A., Leclerc M.Y., Karipot A., Zhang G., and Vesala T., 2005. Effect of clearcuts on footprints and flux measurements above a forest canopy. Agric. For. Meteorol., 133: 182-196.

Sogachev A., Leclerc M.Y., Zhang G., Rannik Ü., and Vesala T., 2008. $\mathrm{CO}_{2}$ fluxes near a forest edge: A numerical study. Ecol. Appl., 18: 1454-1469.

Sogachev A., Rannik Ü., and Vesala T., 2004. Flux footprints over complex terrain covered by heterogeneous forest. Agric. For. Meteorol., 127: 143-158.

Sogachev A. and Sedletski A., 2006. SCADIS "Footprint calculator": Operating manual. Proc. BACCI, NECC and FCoE activities 2005, (Eds M. Kulmala, A. Lindroth and T.M. Ruuskanen). Aerosolitutkimusseura, Helsinki.

Steinfeld G., Raasch S., and Markkanen T., 2008. Footprints in Homogeneously and Heterogeneously Driven Boundary Layers Derived from a Lagrangian Stochastic Particle Model Embedded into Large-Eddy Simulation. Bound. Lay. Met., 129: 225-248.

Tramontana G., Jung M., Schwalm C.R., Ichii K., CampsValls G., Ráduly B., et al., 2016. Predicting carbon dioxide and energy fluxes across global FLUXNET sites with regression algorithms. Biogeosciences, 13: 4291-4313, doi:10.5194/bg-13-4291-2016.

van Jaarsveld A.S., Pauw J.C., Mundree S., Mecenero S., Coetzee B.W.T., and Alard G.F., 2007. South African Environmental Observation Network: vision, design and status. South African J. Sci., 103: 289-294.

Vesala T., Kljun N., Rannik Ü., Rinne J., Sogachev A., Markkanen T., et al., 2008. Flux and concentration footprint modelling: State of the Art. Environ. Pollut. 152: 653-666. doi:doi:10.1016/j.envpol.2007.06.070.

Vickers D. and Mahrt L., 1997. Quality control and flux sampling problems for tower and aircraft data. J. Atmos. Ocean. Technol., 14: 512-526.

Vogt R. and Feigenwinter C., 2011. Angle of attack performance of five different sonic anemometers in a wind tunnel. Nordflux Workshop on the Accuracy of Eddy Covariance Flux Measurements. Roskilde, Denmark.

Vogt R., Feigenwinter C., Paw U K.T., and Pitacco A., 1997. Intercomparison of ultrasonic anemometers. 12th Symp. Boundary Layers and Turbulence, Vancouver, Canada. Am. Met. Soc., Vancouver, Canada. 
Webb E.K., Pearman G.I., and Leuning R., 1980. Correction of the flux measurements for density effects due to heat and water vapour transfer. Quart. J. Roy Meteorol. Soc. 106. doi:10.1002/qj.49710644707.

Welles J.M. and McDermitt D.K., 2005. Measuring carbon dioxide in the atmosphere. Micrometeorology in Agricultural Systems Agron. Monogr., 47, 287-320.

World MeteorologicalOrganization(WMO), 2008. Guide to Meteorological Instruments and Methods of Observation, WMO-No. 8. World Meteorological Organization.

World Meteorological Organization (WMO), 2014. updated in 2017. Guide to Meteorological Instruments and Methods of Observation, WMO-No. 8. World Meteorol. Organization.

Wyngaard J.C., 1981. The Effects of Probe-Induced Flow Distortion on Atmospheric Turbulence Measurements. J. Appl. Meteorol., 20: 784-794.
Wyngaard J.C., 1988. The Effects of Probe-Induced Flow Distortion on Atmospheric Turbulence Measurements: Extension to Scalars. J. Atmos. Sci. 45: 3400-3412. doi:10.1175/1520-0469(1988)045<3400:TEOPIF $>2.0$. $\mathrm{CO} ; 2$.

Yamamoto S., Saigusa N., Gamo M., Fujinuma Y., Inoue G., and Hirano T., 2005. Findings through the AsiaFlux network and a view toward the future. J. Geographical Sci., 15: 142-148. doi:10.1007/bf02872679.

Zscheischler J., Mahecha M.D., Avitabile V., Calle L., Carvalhais N., Ciais P., et al., 2017. Reviews and syntheses: An empirical spatiotemporal description of the global surface-atmosphere carbon fluxes: opportunities and data limitations. Biogeosciences, 14: 3685-3703. doi:10.5194/bg-14-3685-2017. 
Appendix

\section{A1: EC tower requirements}

General requirements for placement and design of the EC tower:

- The area around the tower has to be large enough to provide sufficient fetch in all desired wind directions (see section on spatial representativeness).

- The surface should ideally be flat and homogeneous.

- Flow distortion by tower structure and chimney effects have to be minimized.

- The prevailing wind direction, local circulation patterns, as well as day/night and seasonal patterns of the wind direction should be determined in advance of setting up the tower.

- Practical requirements such as power availability (line power is mandatory for Class 1 and Class 2 stations) and year-round accessibility of the site for maintenance should be considered during the planning stage.

- The tower structure has to be robust, stable and able to withstand environmental extremes such as the strong winds and ice loads.

- The tower has to provide safe access to the instrumentation for field staff including the ability to carry equipment up to the instruments location.

- Instruments have to be placed on the tower so that their exposure time to the desired land cover type is maximized and flow distortion from supporting structures and other instruments is minimized.

- $\quad$ Tower and instruments should be reasonably protected against damage from lightning, birds and insects.

Tower deflection and oscillations (based on Munger et al., 2012)

- Any movement in the tower that co-varies either with the turbulent fluctuations of wind speed or a scalar of interest contributes to systematic uncertainty in the measurements.

- Movement of the tower should be restricted to $0.02 \mathrm{~m} \mathrm{~s}^{-1}$ (i.e. the accuracy to measure wind speed), and should not have moments that co-vary with the wind between 1 and $20 \mathrm{~Hz}$ (harmonic effect).

- Fast-response accelerometers can be used to quantify tower motion. Point-by-point corrections would require also fast response inclinometer measurements to determine the rotation rate vector as well as the acceleration vector.

- Note that tower movement due to personnel working on the tower does not co-vary with wind or scalar exchange but might disturb the wind field.

Placement of the tower and dimension of mast

- At the wind facing side (upstream) of the tower the wind speed decreases. The upwind distance that is affected by flow distortion is proportional to the cube of the obstacle size and decreases with the cube of the distance (Wyngaard, 1981, 1988).

- At the lee side (downstream) of the tower, wind speeds are also attenuated. This effect reduces with increasing wind speed (more rapid restructuring of the turbulent flow) and is affected by the length and width of the obstacle.

- Chimney effects are observed when heating of the tower base and structure induces convective circulation that reinforces the vertical deflection of the airflow, thus moving even more air up. Chimney effects depend on the mass and heat capacity of the foundation and the tower, the shape of the tower, the degree of disturbance to the canopy (clearing/cutting trees for tower construction) and the amount of net radiation at the station. These effects are unavoidable but should be minimized by minimizing the concrete foundation and tower structure. 
Specific requirements/suggestions for instrument placement on booms

- Radiation sensors should ideally be positioned $1.5 \mathrm{~m}$ away from the tower structure (see Carrara et al., this issue). To ensure regular cleaning of the sensors, especially on tall towers, the boom has to be movable and proper levelling has to be ensured.

- Each boom shall be able to support total equipment weight, regardless of the position on the boom and weather conditions.

- The vertical position of the boom arms shall have a maximum tolerance of $\pm 0.1 \mathrm{~m}$ around the intended mounting heights.

- The horizontal and vertical mounting angles of the instruments (radiation, rain, wind, wind direction should be accurate within \pm 5 degrees.

- In order to enable the reliable determination of an aerodynamic plane for eddy-covariance flux measurements, periods of maintenance work on the eddy-covariance boom or on sensors attached to it have to be recorded via the BADM system.

- The movement of all sonic anemometers can be measured with an automated 3-Axis Accelerometer and a 2-axis inclinometer.

- To ensure proper functioning of the IRGA, the supporting infrastructure to which the IRGA head and the inlet is attached shall avoid vibrations in the frequency range from $130 \mathrm{~Hz}$ to $170 \mathrm{~Hz}$ (LI-COR, 2014).

A2: High-resolution sonic anemometer variables

- 3 Cartesian wind velocity components, instrument-aligned coordinates: $u, v, w\left[\mathrm{~m} \mathrm{~s}^{-1}\right]$, where $(u, v, w)$ is a right-hand system on Cartesian space $(x, y, z)$, so that $u(x)$ is aligned with the instrument arm (positive in direction of the sensor head) and $w(z)$ is pointing upward.

- $\quad$ Sonic temperature: $T_{\text {sonic }}[\mathrm{K}]$, derived from transit times $[\mathrm{s}]$ and speed of sound $\left[\mathrm{ms}^{-1}\right]$ )

Auxiliary sonic data

- Inclinometer values (x- and y-axes) [degrees]

- $\quad$ Diagnostic value from instrument [-]

All variables available from the sonic anemometer that have to be acquired are listed in Table 2 and in case of updates can be accessed via http://www.icos-etc.eu/icos/documents/instructions.

\section{A3: General Gas Sampling System (GSS) dimensioning}

In summary, all constraints on the filter type, tube dimensions and flow rate are:

- A cell renewal rate of at least 10 volume exchanges per second, implying a flow rate larger than $9.6 \mathrm{sl}$ $\min ^{-1}$

- A transfer function cut-off frequency determined on power spectra as high as possible (ideally above 3 $\mathrm{Hz}$ )

- A pressure drop in the cell that is lower than $10 \mathrm{kPa}$ (if using the LI-7200-101 flow module, this limit is reduced to $3.5 \mathrm{kPa})$.

\section{A4: Sensor Calibration Procedures}

All eddy covariance instrumentation including the sensors for companion variables has to be calibrated every second year in the factory or by local sellers. Cross-comparison performed with other higher quality sensors available at the site can be performed more frequently. In an optimized network, the best solution would be to circulate a set of reference instruments owned by the TC and circulated across the sites on a regular basis.

For air temperature, moisture, and air pressure standardised calibration and re-calibration procedures have to be performed every 2 years or as specified by the ETC. 


\section{A5: Technical Issues on EC data Acquisition Software}

It has to be ensured that the hardware settings in the data acquisition software tools are correct and appropriate. Depending on the software, measurement frequency, number and order of additional analogue or serial input channels have to be specified. The sonic anemometer azimuth alignment has to be fixed in the acquisition software and be stored as meta-data to get horizontal wind components directly as an output, especially when the real-time calculation of fluxes and wind direction is required, but also to enable correct post-processing.

\section{Sampling frequency}

The sampling frequency should be set to $20 \mathrm{~Hz}$ whenever possible but certainly above smooth surfaces. $10 \mathrm{~Hz}$ is sufficient over forests and is the minimum requirement within the ICOS network. To correlate simultaneous measurements, the IRGA and the 3D-sonic anemometer electronic sampling lag time (to be avoided by above data acquisition schemes) shall be reported to the cyberinfrastructure system with an accuracy of $\pm 1 \mathrm{~ms}$. Each recorded sample must have a timestamp. The maximum accepted drift of clocks between IRGA and sonic is one sample size, e.g. $1 / 20 \mathrm{~s}$ at $20 \mathrm{~Hz}$, but ultimately should be avoided.

Near real-time raw data should be transferred to both the site investigator and the Carbon Portal (https://www.icos$\mathrm{cp.eu/)} \mathrm{to} \mathrm{provide} \mathrm{the} \mathrm{opportunity} \mathrm{for} \mathrm{an} \mathrm{instant} \mathrm{feedback.} \mathrm{Fluxes} \mathrm{may} \mathrm{be} \mathrm{calculated} \mathrm{on} \mathrm{site} \mathrm{and} \mathrm{all} \mathrm{diagnostics}$ have to be stored to ensure the possibility of offline quick looks for immediate reactions in case of problems with the system. Preferably, data should be compressed (i.e., zip file bundles) before sending to help minimize bandwidth and the possibility of communication breakdowns when transferring larger unzipped files.

Data transmission to the Carbon Portal

Data must be stored at a raw level, i.e. with a logging frequency equal to the sampling frequency and be provided in 30-min ASCII (zip) or binary (TOB1) files to the Carbon Portal including all necessary meta data.

Table A1: List of mandatory variables from infrared gas analyser and sonic anemometer required for ICOS ecosystem stations (Class 1 and 2).

\begin{tabular}{|c|c|c|}
\hline Variable description & ICOS label & SI Unit \\
\hline $1^{\text {st }}$ horizontal sonic wind component (x-direction) & $\mathrm{U}$ & $\mathrm{m} \mathrm{s}^{-1}$ \\
\hline $2^{\text {nd }}$ horizontal sonic wind component (y-direction) & V & $\mathrm{m} \mathrm{s}^{-1}$ \\
\hline Vertical sonic wind component (z-direction) & $\mathrm{W}$ & $\mathrm{m} \mathrm{s}^{-1}$ \\
\hline Sonic temperature & T_SONIC & $\mathrm{K}$ \\
\hline Sonic status type indicator & SA_DIAG_TYPE & - \\
\hline Sonic status value (hexadecimal) & SA_DIAG_VALUE & - \\
\hline $\mathrm{CO}_{2}$ concentration density & $\mathrm{CO} 2 \_\mathrm{CONC}$ & $\mathrm{mmol} \mathrm{m} \mathrm{m}^{-3}$ \\
\hline $\mathrm{H}_{2} \mathrm{O}$ concentration density & $\mathrm{H} 2 \mathrm{O} \_\mathrm{CONC}$ & $\mathrm{mmol} \mathrm{m} \mathrm{m}^{-3}$ \\
\hline $\mathrm{CO}_{2}$ raw power in the sample wavelength & CO2_POW_SAM & - \\
\hline $\mathrm{H}_{2} \mathrm{O}$ raw power in the sample wavelength & H2O_POW_SAM & - \\
\hline $\mathrm{CO}_{2}$ raw power in the reference wavelength & CO2_POW_REF & - \\
\hline $\mathrm{H}_{2} \mathrm{O}$ raw power in the reference wavelength & H2O_POW_REF & - \\
\hline $\mathrm{CO}_{2}$ molar fraction (in humid air) & $\mathrm{CO} 2^{-}-$ & $\mu \mathrm{mol} \mathrm{mol}{ }^{-1}$ \\
\hline $\mathrm{H}_{2} \mathrm{O}$ molar fraction (in humid air) & $\mathrm{H} 2 \mathrm{O}$ & $\mathrm{mmol} \mathrm{mol}^{-1}$ \\
\hline $\mathrm{CO}_{2}$ dry mole fraction (in dry air) & CO2_DRY & $\mu \mathrm{mol} \mathrm{mol}{ }^{-1}$ \\
\hline $\mathrm{H}_{2} \mathrm{O}$ dry mole fraction (in dry air) & H2O_DRY & $\mathrm{mmol} \mathrm{mol}^{-1}$ \\
\hline Temperature of the measurement cell & T_CELL & degree $\mathrm{C}$ \\
\hline Cell temperature where the samples enters the cell & T_CELL_IN & degree $\mathrm{C}$ \\
\hline Cell temperature where the samples exits the cell & T_CELL_OUT & degree $\mathrm{C}$ \\
\hline Pressure in the measurement cell & PRESS_CELL & $\mathrm{kPa}$ \\
\hline Difference of pressure between cell and box & PRESS_DELTA & $\mathrm{kPa}$ \\
\hline Flow pressure in the sampling line & FLOW_PRESS & $\mathrm{kPa}$ \\
\hline Volume flow rate in the sampling line & FLOW_VOLRATE & $1 \min ^{-1}$ \\
\hline Diagnostic value of GA (16bit binary) & GA_DIAG_CODE & - \\
\hline Power provided to the tube for heating & GA_TUBE_HEAT & $\mathrm{W}$ \\
\hline Voltage provided to the tube for heating & GA_TUBE_HEAT_V & $\mathrm{V}$ \\
\hline
\end{tabular}




\section{A6: Definitions}

\section{Step response time}

The duration between the instant when an input quantity value of a measuring instrument or measuring system is subjected to an abrupt change between two specified constant quantity values and the instant when a corresponding indication settles within specified limits around its final steady value.

\section{Measurement accuracy}

The accuracy specifies the closeness of agreement between a measured quantity value and a true quantity value of a variable.

\section{Measurement precision}

The precision specifies the closeness of agreement between indications or measured quantity values obtained by replicate measurements on the same or similar objects under specified conditions.

Sensitivity of a measuring system

The sensitivity specifies the quotient of the change in an indication of a measuring system and the corresponding change in a value of a quantity being measured. 